\title{
FEED SYSTEM INNOVATION FOR GASIFICATION OF LOCALLY ECONOMICAL ALTERNATIVE FUELS (FIGLEAF)
}

\author{
Annual Technical Report \\ For the period September 1, 2000, to September 30, 2001 \\ Prepared for: \\ AAD Document Control \\ U.S. Department of Energy \\ National Energy Technology Laboratory \\ PO Box 10940, MS 921-107 \\ Pittsburgh, PA 15236-0940 \\ DOE Agreement No. DE-FC26-00NT40904
}

Prepared by:

Michael L. Swanson

Mark A. Musich Darren D. Schmidt

Energy \& Environmental Research Center University of North Dakota

Box 9018

Grand Forks, ND 58202-9018 


\section{DOE DISCLAIMER}

This report was prepared as an account of work sponsored by an agency of the United States Government. Neither the United States Government, nor any agency thereof, nor any of their employees makes any warranty, express or implied, or assumes any legal liability or responsibility for the accuracy, completeness, or usefulness of any information, apparatus, product, or process disclosed or represents that its use would not infringe privately owned rights. Reference herein to any specific commercial product, process, or service by trade name, trademark, manufacturer, or otherwise does not necessarily constitute or imply its endorsement, recommendation, or favoring by the United States Government or any agency thereof. The views and opinions of authors expressed herein do not necessarily state or reflect those of the United States Government or any agency thereof.

This report is available to the public from the National Technical Information Service, U.S. Department of Commerce, 5285 Port Royal Road, Springfield, VA 22161; phone orders accepted at (703) $487-4650$.

\section{ACKNOWLEDGMENT}

This report was prepared with the support of the U.S. Department of Energy (DOE) National Energy Technology Laboratory Cooperative Agreement No. DE-FC26-00NT40904. However, any opinions, findings, conclusions, or recommendations expressed herein are those of the authors(s) and do not necessarily reflect the views of DOE.

\section{EERC DISCLAIMER}

LEGAL NOTICE This research report was prepared by the Energy \& Environmental Research Center (EERC), an agency of the University of North Dakota, as an account of work sponsored by DOE and Global Energy. Because of the research nature of the work performed, neither the EERC nor any of its employees makes any warranty, express or implied, or assumes any legal liability or responsibility for the accuracy, completeness, or usefulness of any information, apparatus, product, or process disclosed, or represents that its use would not infringe privately owned rights. Reference herein to any specific commercial product, process, or service by trade name, trademark, manufacturer, or otherwise does not necessarily constitute or imply its endorsement or recommendation by the EERC. 


\title{
FEED SYSTEM INNOVATION FOR GASIFICATION OF LOCALLY ECONOMICAL ALTERNATIVE FUELS (FIGLEAF)
}

\begin{abstract}
The Feed System Innovation for Gasification of Locally Economical Alternative Fuels (FIGLEAF) project is being conducted by the Energy \& Environmental Research Center and Gasification Engineering Corporation of Houston, Texas (a subsidiary of Global Energy Inc., Cincinnati, Ohio), with $80 \%$ cofunding from the U.S. Department of Energy. The goal of the project is to identify and evaluate low-value fuels that could serve as alternative feedstocks and to develop a feed system to facilitate their use in integrated gasification combined cycle and gasification coproduction facilities. The long-term goal, to be accomplished in a subsequent project, is to install a feed system for the selected fuels at Global Energy's commercial-scale 262-MW Wabash River Coal Gasification Facility in West Terre Haute, Indiana.
\end{abstract}

The feasibility study undertaken for the project consists of identifying and evaluating the economic feasibility of potential fuel sources, developing a feed system design capable of providing a fuel at 400 psig to the second stage of the E-Gas (Destec) gasifier to be cogasified with coal at up to $30 \%$ on a Btu basis, performing bench- and pilot-scale testing to verify concepts and clarify decision-based options, reviewing prior art with respect to high-pressure feed system designs, and determining the economics of cofeeding alternative feedstocks with the conceptual feed system design.

Activities and results thus far include the following. Several potential alternative fuels have been obtained for evaluation and testing as potential feedstocks, including sewage sludge, used railroad ties, urban wood waste, municipal solid waste, and used waste tires/tire-derived fuel. Only fuels with potential tipping fees were considered; potential energy crop fuels were not considered since they would have a net positive cost to the plant. Based on the feedstock assessment, sewage sludge has been selected as one of the primary feedstocks for consideration at the Wabash plant. Because of the limited waste heat available for drying and the ability of the gasifier to operate with alternative feedstocks at up to $80 \%$ moisture, a decision was made to investigate a pumping system for delivering the as-received fuel across the pressure boundary. High-temperature drop-tube furnace tests were conducted to determine if explosive fragmentation of high-moisture sludge droplets could be expected, but showed that these droplets underwent a shrinking and densification process that implies that the sludge will have to be well dispersed when injected into the gasifier. Fuel dispersion nozzles have been obtained for measuring how well the sludge can be dispersed in the second stage of the gasifier.

Future work will include leasing a Schwing America pump to test pumping sewage sludge against 400 psig. In addition, sludge dispersion testing will be completed using two different dispersion nozzles to determine their ability to generate sludge particles small enough to be entrained out of the E-Gas entrained-flow gasifier. 


\section{TABLE OF CONTENTS}

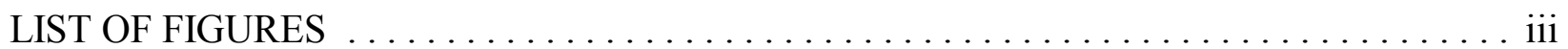

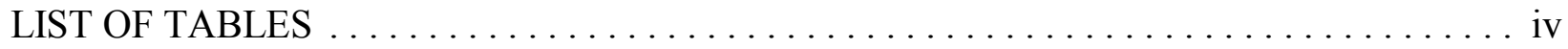

EXECUTIVE SUMMARY $\ldots \ldots \ldots \ldots \ldots \ldots \ldots \ldots \ldots \ldots \ldots \ldots \ldots \ldots \ldots \ldots$

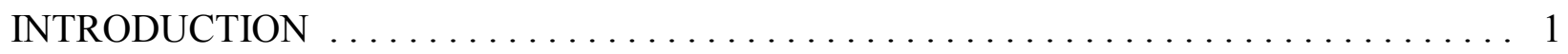

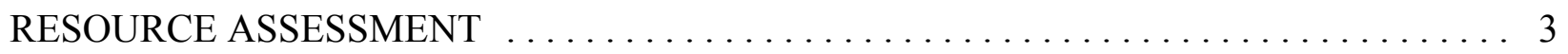

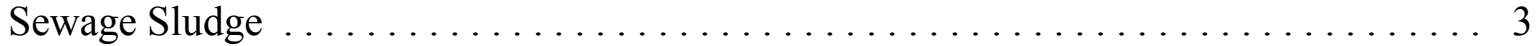

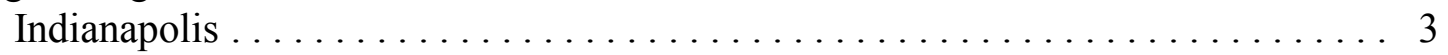

Metropolitan Water Reclamation District of Greater Chicago ............ 4

Regional Cities ..................................... 6

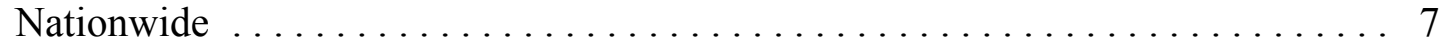

Used Railroad Ties . . . . . . . . . . . . . . . . . . . . . . . . . . . . 7

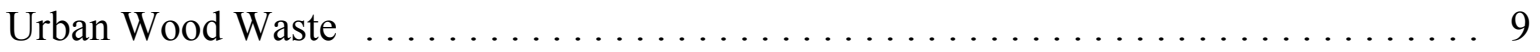

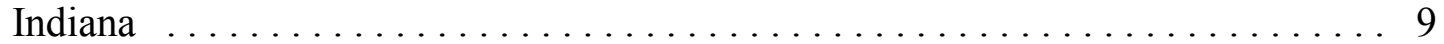

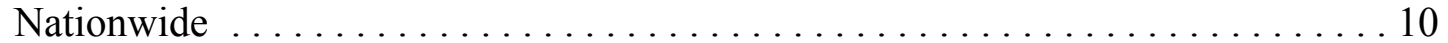

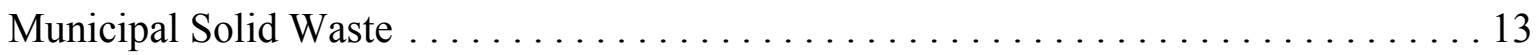

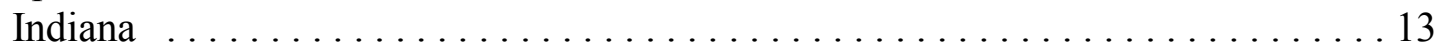

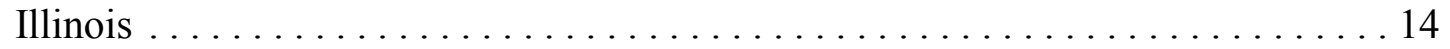

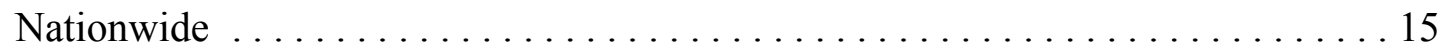

Waste Tires/Tire-Derived Fuel . . . . . . . . . . . . . . . . . . . . . . . . . . 17

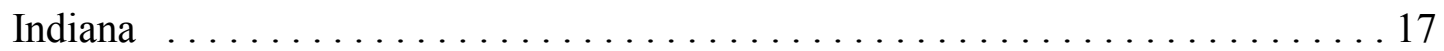

Illinois ............................................ 17

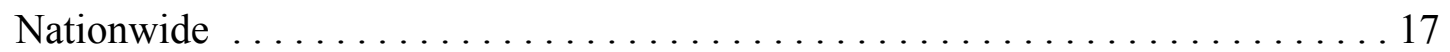

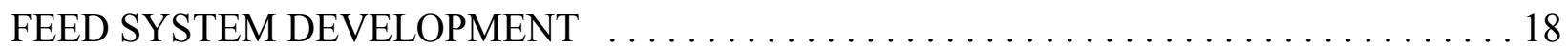

Estimation of Terminal Velocities for Feedstocks . . . . . . . . . . . . . . . . . 18

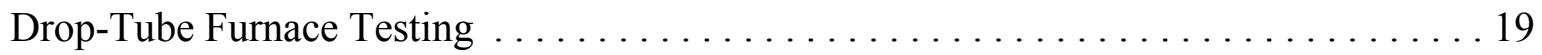

Sewage Sludge Feeding Across Pressure Boundary $\ldots \ldots \ldots \ldots \ldots \ldots \ldots \ldots \ldots$

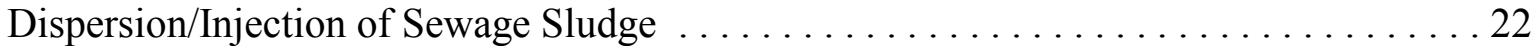

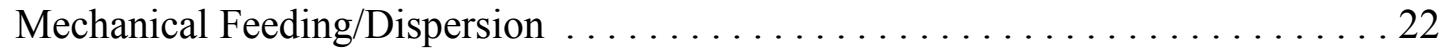

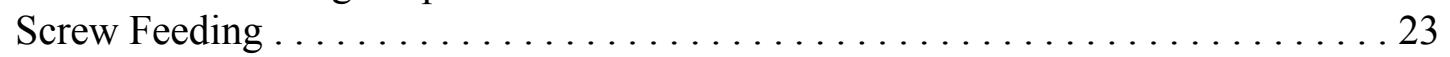

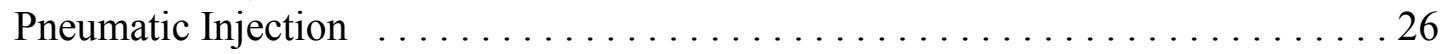

EVALUATION OF FEED SYSTEM COMPONENTS $\ldots \ldots \ldots \ldots \ldots \ldots \ldots \ldots \ldots \ldots \ldots \ldots$

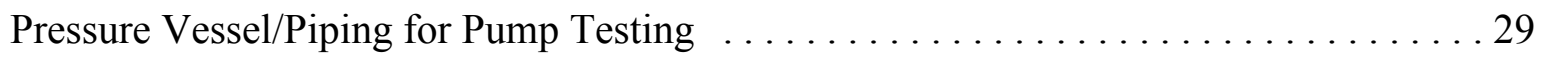

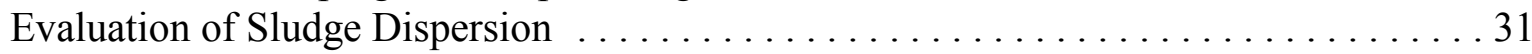

Continued... 


\section{TABLE OF CONTENTS (continued)}

PATENT DATABASE SEARCH FOR HIGH-PRESSURE SOLIDS FEED SYSTEMS . . . 32 PROCUREMENT OF SAMPLES AND SAMPLE ANALYSIS $\ldots \ldots \ldots \ldots \ldots \ldots \ldots \ldots$ COMMERCIAL DRY BIOMASS FEED SYSTEMS $\ldots \ldots \ldots \ldots \ldots \ldots \ldots \ldots \ldots$

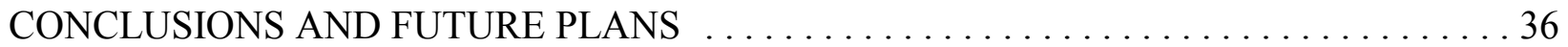

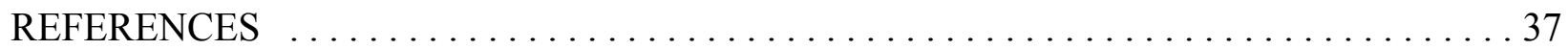

PARAMETERS FOR TERMINAL VELOCITY EQUATIONS . . . . . . . Appendix A PATENTED HIGH-PRESSURE COAL FEED SYSTEMS . . . . . . . . Appendix B RDF FRACTION PHOTOGRAPHS $\ldots \ldots \ldots \ldots \ldots \ldots \ldots \ldots \ldots \ldots \ldots \ldots \ldots \ldots \ldots \ldots$ Appendix C 


\section{LIST OF FIGURES}

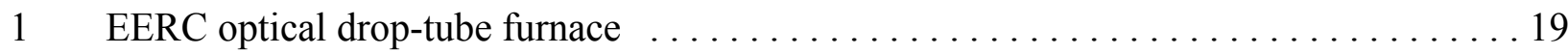

2 Present value analysis for pumps reviewed for sewage sludge pumping into pressurized

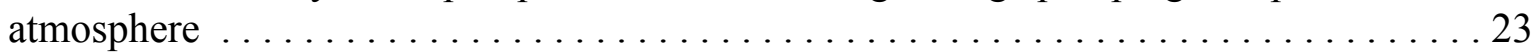

3 Schwing America high-solids sludge pump with twin-screw feeder . . . . . . . . . . . 24

4 Morgen Mustang trailer-mounted concrete $\operatorname{pump} \ldots \ldots \ldots \ldots \ldots \ldots \ldots \ldots \ldots$

5 Cutaway diagram of Morgen Mustang concrete pump $\ldots \ldots \ldots \ldots \ldots \ldots \ldots \ldots$

6 Cutaway diagram of Shotcrete Technologies shotcrete nozzle $\ldots \ldots \ldots \ldots \ldots \ldots$

7 Shotcrete Technologies $2 \frac{1}{2} 2$-inch shotcrete nozzle $\ldots \ldots \ldots \ldots \ldots \ldots \ldots \ldots \ldots \ldots$

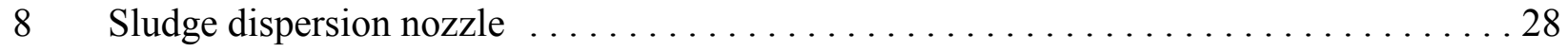

$9 \quad$ Large pressure vessel for elevated-pressure sludge system . . . . . . . . . . . . . . 29

10 Pressure piping system for elevated-pressure sludge pump testing $\ldots \ldots \ldots \ldots \ldots$

11 Sludge dispersion and entrainment column $\ldots \ldots \ldots \ldots \ldots \ldots \ldots \ldots \ldots \ldots \ldots \ldots$ 


\section{LIST OF TABLES}

1 Analysis Results for Indianapolis Sewage Sludge $\ldots \ldots \ldots \ldots \ldots \ldots \ldots$

2 Disposal Methods for $65 \mathrm{wt} \%$ Treated Sludge (biosolids) from the Chicago MWRD . . 6

3 Sludge Available from Regional Cities $\ldots \ldots \ldots \ldots \ldots \ldots \ldots \ldots \ldots \ldots$

4 Estimated Generation of Undigested Sewage Sludge for the 35 Largest U.S.

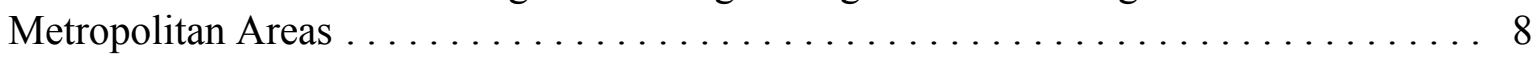

5 Estimate of Available Urban Wood Waste Within Indiana $\ldots \ldots \ldots \ldots \ldots \ldots \ldots \ldots 11$

6 Estimated Generation of Urban Wood Waste for the 35 Largest U.S. Metropolitan

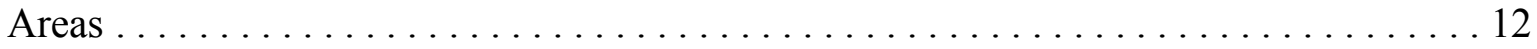

7 MSW Resource Available Within Indiana Counties Adjacent to Terre Haute . . . . . . 14

8 MSW Resource Available Within Illinois Counties Adjacent to Terre Haute . . . . . . . . 15

9 Estimated Generation of Municipal Solid Waste for the 35 Largest U.S. Metropolitan

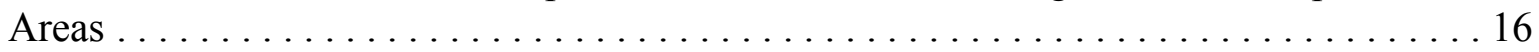

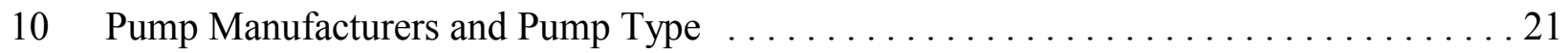

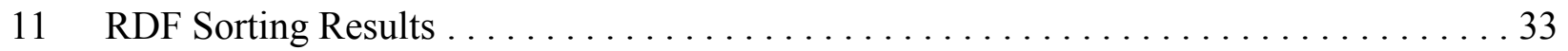

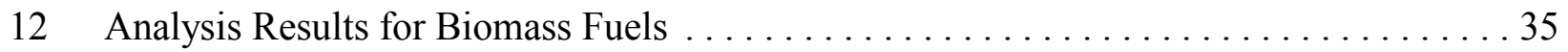

13 Bulk Densities Measured for Select Biomass Materials $\ldots \ldots \ldots \ldots \ldots \ldots$ 


\section{FEED SYSTEM INNOVATION FOR GASIFICATION OF LOCALLY ECONOMICAL ALTERNATIVE FUELS (FIGLEAF)}

\section{EXECUTIVE SUMMARY}

The Feed System Innovation for Gasification of Locally Economical Alternative Fuels (FIGLEAF) project is being conducted by the Energy \& Environmental Research Center (EERC) and Gasification Engineering Corporation of Houston, Texas (a subsidiary of Global Energy Inc., Cincinnati, Ohio), with cofunding from the U.S. Department of Energy. The goal of the project is to identify and evaluate low-value fuels that could serve as alternative feedstocks and to develop a feed system to facilitate their use in integrated gasification combined cycle and gasification coproduction facilities. The long-term goal, to be accomplished in a subsequent project, is to install a feed system for the selected fuels at Global Energy's commercial-scale 262-MW Wabash River Coal Gasification Facility in West Terre Haute, Indiana.

The feasibility study undertaken for the project consists of identifying and evaluating the economic feasibility of potential fuel sources, developing a feed system design capable of providing a fuel at 400 psig to the second stage of the E-Gas (Destec) gasifier to be cogasified with coal at up to $30 \%$ on a Btu basis, performing bench- and pilot-scale testing to verify concepts and clarify decision-based options, reviewing prior art with respect to high-pressure feed system designs, and determining the economics of cofeeding alternative feedstocks with the conceptual feed system design.

Initial project activities included identifying potential alternative feedstocks for use at Global Energy's Wabash River (Terre Haute, Indiana) gasification plant. Estimates were developed for the availability of sewage sludge, used railroad ties, urban wood waste (UWW), municipal solid waste (MSW), and waste tire fuel. Nationwide estimates were also determined for these fuels based on their availability in the 35 largest metropolitan areas of the United States with population over approximately 1.1 million people.

The resource assessment showed that within an approximately 50-mile radius, only MSW is available in sufficient quantity to provide up to $10 \%$ of the thermal input to the Wabash River gasifier. Vigo County, which contains Terre Haute, could provide $7.6 \%$, while the 15 counties with borders within 50 straight-line miles of Terre Haute could provide an additional $20 \%$ thermal input. For UWW, transport distances would be up to 75 miles to attain $10 \%$ or more of the thermal input, with only $2 \%$ of the input sustainable by available UWW within the Vigo County area. The availability of sewage sludge is more limited, with Indianapolis, Indiana (approximately 75 miles from Terre Haute), able to supply up to $5 \%$ of the gasifier thermal input.

Nationwide estimates show a similar trend of availability for MSW and UWW, with metropolitan areas with 1 million people being able to provide over $40 \%$ and $20 \%$, respectively, of the Wabash River gasifier thermal input. For undigested sewage sludge, a metropolitan region of approximately 2.75 million people could provide $10 \%$ of the thermal input. 
Based on the desires of Global Energy, sewage sludge was selected as the alternative fuel around which a feed system will be developed. Undigested sewage sludge with a solids content of approximately $23 \mathrm{wt} \%$ has been selected as the baseline fuel. Preliminary system design intentions preclude any drying of the sludge because of the uncertainty regarding the net tipping fee received at the Wabash River site.

System design activities have determined that pumping using commercially available highpressure sludge pumps will provide the best option for getting the sludge across the pressure boundary. The EERC has leased a commercial pump to demonstrate feeding mechanically dewatered sludge into a pressurized vessel at $410 \mathrm{psig}$. Design and construction activities have been completed on the pressure vessel. Further, the EERC has procured a commercial shotcrete (concrete) nozzle for demonstration of sludge dispersion for injection into the Wabash River entrained-flow gasifier. Estimates for the required sludge particle size have been developed using methods proposed for determination of particle terminal velocities. 


\section{FEED SYSTEM INNOVATION FOR GASIFICATION OF LOCALLY ECONOMICAL ALTERNATIVE FUELS (FIGLEAF)}

\section{INTRODUCTION}

Gasification processes are unique in that they can convert any carbon-based feedstocks to electricity, steam, fuels, chemicals, and hydrogen. The goal of the Feed System Innovation for Gasification of Locally Economical Alternative Fuels (FIGLEAF) project is to identify and evaluate low-value fuels that can serve as alternative feedstocks and develop a feed system to facilitate their use in integrated gasification combined cycle and gasification coproduction facilities. To be economically attractive, gasification must offset the higher capital cost of the gasifier and gas cleanup systems through the use of lower-cost or negative-value fuel sources. In order to broaden and extend the potential applications of gasification and, thus, accrue the environmental and resource advantages, a wider variety of alternative feedstocks needs to be available to commercial plants. In most cases, when alternative feedstocks are cofed, the secondary fuel is likely to be significantly different in physical and chemical properties from the primary coal fuel. Discontinuities and nonuniformities in handling and feeding the differing materials may be expected in some of the feed mechanisms and must be addressed in the design and operation of feed systems to ensure smooth and uniform performance during transient and steady operations.

This project will assess the development of novel feed systems for gasification of selected alternative feedstocks under pressure (i.e., greater than 400 psia). For this research program, cofeeding is defined as feeding a mixture of up to $30 \%$ alternative resource mixed with the primary fuel (coal) into a single gasifier of existing commercially available design. Cofeeding may include, but is not limited to, biomass, municipal solid waste (MSW), sludges, and nonhazardous industrial wastes. This research program is anticipated to include a feasibility study followed by the new design or improvement of feed system equipment with limited pilot-/lab-scale testing. The feasibility study includes the identification and assessment of those issues associated with these alternative feedstocks and will determine their applicability to broadly based markets and uses. Lab or pilot testing is anticipated to provide a versatile base of design information for use of developed feed systems for comixtures.

The project is being conducted by the Energy \& Environmental Research Center (EERC) and Gasification Engineering Corporation of Houston, Texas (a subsidiary of Global Energy Inc., Cincinnati, Ohio). The EERC is one of the world's major energy and environmental research organizations, employing more than 210 full-time professional scientists, engineers, and technicians to conduct research, testing, and evaluation of fuels, combustion, gasification, and emission control technologies. Global Energy is a world leader in gasification for power generation, with over 60,000 hours of coal gasification operational experience and nearly 600 person years of gasification expertise among its employees. Global Energy's E-gas (Destec) technology gasification facility, the Wabash River Coal Gasification Repowering Project, is currently the largest single-train gasification facility operating in the western hemisphere as well as the cleanest coal-fired plant of any kind in the world. This program is cofunded with $\$ 499,000$ of funding from the U.S. Department of Energy (DOE) ( $80 \%$ of the cost of the project) and $\$ 125,000$ of industrial cost share. The long-term goal of 
a subsequent project is to install a feed system for these selected fuels at Global Energy's commercial-scale 262-MW Wabash River Coal Gasification Facility in West Terre Haute, Indiana.

Activities and results thus far include the following:

- Several potential alternative fuels have been obtained for evaluation and testing as potential feedstocks, including sewage sludge, used railroad ties, urban wood waste (UWW), MSW, and used waste tires/tire-derived fuel. Only fuels with potential tipping fees were considered; potential energy crop fuels were not considered since they would have a net positive cost to the plant.

- Based on the feedstock assessment, sewage sludge has been selected as one of the primary feedstocks for consideration at the Wabash plant.

- Because of the limited waste heat available for drying and the ability of the gasifier to operate with alternative feedstocks at up to $80 \%$ moisture, a decision was made to investigate a pumping system for delivering the as-received fuel across the pressure boundary.

- High-temperature drop-tube furnace tests were conducted to determine if explosive fragmentation of high-moisture sludge droplets could be expected, but showed that these droplets underwent a shrinking and densification process that implies that the sludge will have to be well dispersed when injected into the gasifier.

- Fuel dispersion nozzles have been obtained for measuring how well the sludge can be dispersed in the second stage of the gasifier.

Cofiring biomass in the Wabash gasification system will require 1) collection and transportation of fuel; 2) handling, preparation, and feeding of fuel; and 3) cogasification. Feeding the fuel past the pressure boundary of the gasifier is the most critical step. The economics of collection and transportation will be evaluated to identify the specific fuel or mix, and it is expected that biomass will gasify readily and that the residence time is adequate in the second stage of the Wabash gasifier.

Several feeding approaches have been considered, including hydrothermal treatment of biomass, coslurry feed, a unique single-stage solid fuel pressurization device, and densification. The EERC has developed methods for producing liquid fuels through hydrothermal treatment of peat, sewage sludge, automotive shredder residue, refuse-derived fuel (RDF), wood, and coal. Despite energy density increases of $400 \%$, this technology is not being considered because of the higher capital costs of implementation. Also taken into consideration was the implementation of coslurry feeding biomass through the existing slurry equipment. Global Energy prepares coal slurry to the maximum slurry viscosity limits of the pumps, and the addition of biomass to the slurry mixture would result in a significant derating of the plant because of the low fuel energy density. Unique single-state solid fuel pressurization devices exist such as the Stamet Posimetric solids pressure feeder and the Fuller solids pressure auger. Both these devices require prepared material such as 
pulverized coal, which can be compacted to provide a back-pressure seal. Using such a device could greatly limit the type of biomass and the properties of the fuel that could be cofed. Densification was deemed to have capital and operating costs too high for an economic feed system. Based on a preliminary review of these approaches, it was determined that a separate dry feed system in which the fuel would enter the second stage of the Wabash gasifier would be the best, and the following design considerations were determined:

- Limit fuel preparation costs

- Minimize capital investment

- Present a reasonable technical risk

- Handle a wide variety of fuel and size

- Feed across a 400-psi pressure boundary

\section{RESOURCE ASSESSMENT}

\section{Sewage Sludge}

\section{Indianapolis}

The White River Environmental Partnership (WREP) operates two wastewater treatment plants (WWTPs) for the municipality of Indianapolis, treating approximately 200 million gallons/day (MGD) of wastewater (1-3). Approximately 711 wet tons/day of sludge is produced at a solids content of 22 to $23 \mathrm{wt} \%$. Primary and waste-activated sludges are combined and dewatered at the Belmont site, with sludge being transported 7 miles by pipeline between sites. The dewatered sludge is then incinerated at Belmont in a rotary hearth furnace, with the ash residue landfilled as a Type 3 special waste. The elimination of a stabilization or treatment (e.g., digestion) step preserves heating value and reduces the quantity of supplemental fuel (natural gas) required to sustain combustion and achieve proper destruction.

At the time of discussions with Indianapolis contacts, the municipality was pursuing other options for disposal of the sludge. Although incineration is currently cost-competitive with landfilling - the tipping fee would be about $\$ 13 /$ wet ton at the adjacent Southside landfill, and transportation costs would be about $\$ 2 /$ wet ton-negotiations were under way with Southside to allow landfilling of the sludge at only $\$ 5$ to $\$ 6 /$ wet ton. The landfill operators would benefit from enhanced landfill gas production, owing to the wet, biologically active sludge. It was revealed that the sludge could be obtained from Indianapolis if no more than $\$ 15$ to $\$ 16 /$ wet ton was to be paid to the procurer.

Truck haul would be the most probable method of sludge transport between Indianapolis and Terre Haute. The truck haul option would require up to 35 loads per day (at $\sim 20$ ton/truck) over a one-way haul distance of approximately 75 miles. The Belmont site, where sludge dewatering is performed, lacks rail access. 
Truck haul cost estimates were received from two cartage companies for transporting $23 \mathrm{wt} \%$ undigested sludge from the Belmont site to Terre Haute $(4,5)$. The estimates ranged from $\$ 26$ to $\$ 30 /$ wet ton, which would more than consume the tipping fee that could be obtained from WREP.

Subsequent to conversations with WREP personnel, the EERC developed a protocol for handling and shipping undigested sewage sludge. The protocol and shipping container were airfreighted to the Belmont WWTP, and a 1-gallon sample of combined undigested primary-wasteactivated sludge was taken from the discharge of the belt filter press. This material was next-day airfreighted back to the EERC for analysis (proximate, ultimate, heating value, ash $\mathrm{x}$-ray fluorescence [XRF], and total chloride). Analysis results are shown in Table 1 for the Indianapolis sewage sludge. Based on a thermal input of 52.0 billion Btu/day to the Wabash River gasifier, the Indianapolis sludge would provide about $4.8 \%$ of the thermal input. This thermal input value is close to the FIGLEAF project design basis value of $5 \%$ to $10 \%$.

\section{Metropolitan Water Reclamation District of Greater Chicago}

The Metropolitan Water Reclamation District (MWRD) of Greater Chicago serves an equivalent population of over 10.1 million people -5.1 million real people, a commercial/industrial equivalent of 4.5 million people, and a combined sewer overflow equivalent to 0.5 million people (6). The district treats over 1400 MGD of wastewater at seven WWTPs, producing approximately 190,000 dry tons/year of Class B stabilized (anaerobically digested) sludge, called biosolids by the "District" (7). The treated sludges produced at the Stickney site (151,000 dry tons/year) and the Calumet site $(30,000$ dry tons/year) account for over $90 \%$ of the sludge produced by the District $(8,9)$.

The District produces biosolids at two solids contents: $25 \mathrm{wt} \%$ and $65 \mathrm{wt} \%$. The $25 \mathrm{wt} \%$ solids sludge represents approximately $11 \%$ (dry basis) of the total treated sludge produced. All of this material is used for beneficial reuse (application to farmland). The $65 \mathrm{wt} \%$ solids sludge represents the remaining $89 \%$ (dry basis) of the total treated sludge produced. The biosolids are used for a variety of applications, as shown in Table 2. The processing costs include those for digestion, aging, transportation, and tipping (if applicable).

Controlled solids distribution includes a soil amendment on golf courses and athletic fields. This application is possible because the digested sewage sludge is allowed to age in drying ponds for up to 3 years, effectively destroying all pathogens and increasing the solids content to $65 \mathrm{wt} \%$ via natural drying. Disposal in Fulton County entails trucking sludge 162 miles for utilization in a former mine land reclamation program. The majority of the remaining sludge is disposed of within 15 miles of the WWTPs.

Possible modes for the 200-mile sludge transport from Chicago to Terre Haute would include rail haul or truck haul. Rail access is available at the sludge-aging site; however, the rail siding can only handle the light traffic of the side-dump cars that move fresh sludge from the WWTPs to the aging ponds. District personnel believe that significant upgrades would be required to handle daily rail load out. 


\section{TABLE 1}

Analysis Results for Indianapolis Sewage Sludge

\begin{tabular}{|c|c|c|}
\hline & As-Received & Moisture-Free \\
\hline \multicolumn{3}{|l|}{ Proximate, $w t \%$} \\
\hline Moisture & 77.70 & NA \\
\hline Volatile Matter & 14.71 & 65.96 \\
\hline Fixed Carbon & 1.68 & 7.54 \\
\hline Ash & 5.91 & 26.5 \\
\hline \multicolumn{3}{|l|}{ Ultimate, $\mathrm{wt} \%$} \\
\hline Hydrogen & 9.90 & 5.67 \\
\hline Carbon & 8.76 & 39.27 \\
\hline Nitrogen & 1.05 & 4.69 \\
\hline Sulfur & 0.16 & 0.73 \\
\hline Oxygen & 74.23 & 23.14 \\
\hline Ash & 5.91 & 26.5 \\
\hline Heating Value, Btu/lb & 1736 & 7783 \\
\hline Chloride, $\mu \mathrm{g} / \mathrm{g}$ & 400 & 1790 \\
\hline \multicolumn{3}{|l|}{$\mathrm{XRF}, \mathrm{wt} \%$ as oxide } \\
\hline Silicon & & 29.3 \\
\hline Aluminum & & 22.2 \\
\hline Iron & & 9.0 \\
\hline Titanium & & 0.9 \\
\hline Phosphorus & & 18.4 \\
\hline Calcium & & 9.7 \\
\hline Magnesium & & 2.8 \\
\hline Sodium & & 1.1 \\
\hline Potassium & & 1.7 \\
\hline Sulfur & & 4.9 \\
\hline
\end{tabular}

The cost of sludge processing through digestion is approximately $\$ 75 /$ dry ton, while aging adds another $\$ 11 /$ dry ton. Haulage via truck to Fulton County adds the greatest incremental cost—about $\$ 37 /$ dry ton, or about $\$ 475$ per loaded truck at approximately 20 wet tons/truck.

Based on an assumed heating value of $4500 \mathrm{Btu} / \mathrm{lb}$ (10) for the aged sludge, approximately $9.1 \%$ of the thermal input of the Wabash River (or similarly sized) gasifier could be achieved with 190,000 dry tons/year of sludge. A scenario with higher potential may be to obtain the $39 \%$ (66,000 dry tons/year) of aged sludge that is diverted to landfill and Fulton County, although this 


\section{TABLE 2}

Disposal Methods for $65 \mathrm{wt} \%$ Treated Sludge (biosolids) from the Chicago MWRD

\begin{tabular}{lcc}
\hline Disposal Method & \% of Total & Processing Cost, \$/dry ton \\
\hline Daily Cover & 18 & $54-98$ \\
Final Cover & 33 & $54-98$ \\
Controlled Solids Distribution & 10 & $68-110$ \\
Landfilling & 30 & 120 \\
Fulton County & 9 & $99-123$ \\
\hline
\end{tabular}

quantity of sludge would provide only $3.2 \%$ of the gasifier thermal input. The avoided cost of landfilling or transporting the sludge to Fulton County may provide the procurer $\$ 34$ to $\$ 37 /$ dry ton ( $\$ 22$ to $\$ 24 /$ wet ton) which, according to a quote from one cartage company (\$20 to $\$ 23 /$ wet ton) may be sufficient to offset the transport cost to Terre Haute (11). Cost data were not available for rail haul.

At the time of discussions, the District was preparing a request for proposals to attract bids on the development of a sludge pelletization process to convert at least $50 \%$ of the sludge into a highervalue Class A product. This would significantly reduce the sludge available for use in Terre Haute, and the higher-cost disposal options (landfilling and trucking to Fulton County) would probably be eliminated first.

\section{Regional Cities}

Table 3 lists several other cities within approximately 100 miles of Terre Haute that were contacted to determine quantities and disposition of municipal sewage sludge. These cities all produce digested sewage sludge but in insufficient quantity to be a viable fuel source for Wabash River. The electrical power production potential is below $0.5 \mathrm{MW}$ for any of these cities, assuming $5000 \mathrm{Btu} / \mathrm{lb}$ and $35 \%$ overall efficiency.

\section{TABLE 3}

Sludge Available from Regional Cities

\begin{tabular}{lccccc}
\hline City & $\begin{array}{c}\text { Population, } \\
\text { thousands }\end{array}$ & $\begin{array}{c}\text { Distance, } \\
\text { miles }\end{array}$ & $\begin{array}{c}\text { Sludge, } \\
\text { dry tons/year }\end{array}$ & $\begin{array}{c}\text { Sludge Solids, } \\
\mathrm{wt} \%\end{array}$ & Disposition \\
\hline Evansville, IN & 126 & 112 & - & - & Land-applied \\
Decatur, IL (12) & 80 & 106 & 4690 & 4.5 & Land-applied \\
Lafayette, IN (13) & 70 & 92 & 2500 & 5.0 & Land-applied \\
Champaign, IL $^{1}$ (14) & 97 & 106 & 3600 & 20.0 & Land-applied \\
Bloomington, IN (15) & 61 & 57 & 2920 & 40.0 & Daily cover \\
Danville, IL & 36 & 57 & - & - & - \\
\hline
\end{tabular}

\footnotetext{
${ }^{1}$ Includes the city of Urbana, IL.
} 


\section{Nationwide}

Based on a per capita factor of 0.25 dry lb/day (16), the production of raw or untreated sewage sludge was estimated for the 35 U.S. metropolitan areas with populations over 1 million. The results are presented in Table 4. Using a heating value similar to that of undigested Indianapolis sewage sludge $-7780 \mathrm{Btu} / \mathrm{lb}$ - further estimates show that sludge from 16 of the metro areas could provide $10 \%$ or more of the thermal input to a Wabash River-sized gasifier. The population base required to achieve the $10 \%$ value is approximately 3 million. The remaining metro areas would provide between $5 \%$ and $10 \%$ of the thermal input. Population data were based on preliminary results of the year 2000 census (17).

It should be noted that metropolitan Chicago in Table 4 shows about 8 million people relative to the 5 million people served by the MWRD of Chicago. The six counties within Illinois that surround Cook County contribute the additional 3 million people. The results also show that significantly greater thermal input can be achieved using undigested sludge relative to the digested, aged sludge of the MWRD. Utilizing the undigested sludge would have the benefit of increasing the quantity and heating value of the fuel. Presuming that undigested sludge can be obtained, the avoided cost of digestion would translate into a greater tipping fee for the sludge recipient.

\section{Used Railroad Ties}

Wood tie replacement by Class I railroads over the last several years has ranged from approximately 10.5 to 12.0 million ties, while wood tie replacement for short-line/regional railroads has ranged from 3.5 to almost 4.5 million ties $(18,19)$. Class I railroads operate 170,000 miles of track in the United States. Four railroads-Norfolk Southern (NS), Burlington Northern Sante Fe (BNSF), Union Pacific, and CSX Corporation - operate the majority of the track (20). There are approximately 425 smaller operators - short-line and regional railroads - that operate about 50,000 miles of track.

NS and CSX each have an annual tie replacement of about 2.5 million, including ties replaced on Conrail lines under joint NS-CSX ownership. Union Pacific has annual tie replacement approaching 3 million (21-23). Although information was not available, it is presumed that BNSF tie replacement would be similar in quantity to the other operators. The amount of used ties produced by any one short-line/regional railroad would be small in comparison.

Depending upon moisture content, 1 to 1.5 million used ties are equivalent to about 100,000 tons of used ties (24). At approximately $6800 \mathrm{Btu} / \mathrm{lb}, 140,000$ tons, or 1.7 million, ties would be required annually to supply $10 \%$ of the thermal input to a Wabash River-sized gasifier. This represents about $15 \%$ of the annual used-tie production potential from Class I railroads. However, even though the quantity for a Wabash River-sized gasifier would seemingly be easily

satisfied, competition for the used ties appears strong, and utilization in secondary markets appears very high.

As indicated by discussions with railroad personnel, railroads are not in the business of finding markets for the used ties. Separate used-tie contractors bid for long-term contracts to follow tie 


\section{TABLE 4}

Estimated Generation of Undigested Sewage Sludge for the 35 Largest U.S. Metropolitan Areas

\begin{tabular}{|c|c|c|c|}
\hline City & $\begin{array}{l}\text { Population, } \\
\text { millions }\end{array}$ & $\begin{array}{c}\text { Sludge, } \\
\text { thousand dry tons/year }\end{array}$ & $\begin{array}{l}\% \text { of Gasifier } \\
\text { Thermal Input }\end{array}$ \\
\hline New York, NY & 15.000 & 684 & 56.1 \\
\hline Los Angeles, CA & 13.000 & 593 & 48.6 \\
\hline Chicago, IL & 8.008 & 365 & 30.0 \\
\hline San Francisco, $\mathrm{CA}^{1}$ & 6.188 & 282 & 23.1 \\
\hline Philadelphia, PA & 5.999 & 274 & 22.4 \\
\hline Dallas, $\mathrm{TX}^{2}$ & 4.910 & 224 & 18.4 \\
\hline Washington, DC & 4.740 & 216 & 17.7 \\
\hline Detroit, MI & 4.475 & 204 & 16.7 \\
\hline Houston, TX & 4.011 & 183 & 15.0 \\
\hline Atlanta, GA & 3.857 & 176 & 14.4 \\
\hline Miami, FL & 3.711 & 169 & 13.9 \\
\hline Boston, MA & 3.297 & 150 & 12.3 \\
\hline Seattle, WA & 3.260 & 149 & 12.2 \\
\hline Phoenix, $\mathrm{AZ}^{3}$ & 3.014 & 138 & 11.3 \\
\hline Minneapolis, $\mathrm{MN}^{4}$ & 2.872 & 131 & 10.7 \\
\hline San Diego, CA & 2.821 & 129 & 10.6 \\
\hline St. Louis, MO & 2.569 & 117 & 9.6 \\
\hline Baltimore, MD & 2.491 & 114 & 9.3 \\
\hline Pittsburgh, PA & 2.331 & 106 & 8.7 \\
\hline Tampa, FL $^{5}$ & 2.278 & 104 & 8.5 \\
\hline Cleveland, $\mathrm{OH}$ & 2.221 & 101 & 8.3 \\
\hline Denver, CO & 1.979 & 90.3 & 7.4 \\
\hline Portland, OR & 1.846 & 84.2 & 6.9 \\
\hline Kansas City, MO & 1.756 & 80.1 & 6.6 \\
\hline Cincinnati, $\mathrm{OH}$ & 1.628 & 74.3 & 6.1 \\
\hline Sacramento, CA & 1.585 & 72.3 & 5.9 \\
\hline San Antonio, TX & 1.565 & 71.4 & 5.9 \\
\hline Norfolk, VA & 1.563 & 71.3 & 5.8 \\
\hline Indianapolis, IN & 1.537 & 70.1 & 5.7 \\
\hline Orlando, FL & 1.535 & 70.0 & 5.7 \\
\hline Columbus, $\mathrm{OH}$ & 1.489 & 67.9 & 5.6 \\
\hline Milwaukee, WI & 1.462 & 66.7 & 5.5 \\
\hline Charlotte, $\mathrm{NC}$ & 1.417 & 64.7 & 5.3 \\
\hline New Orleans, LA & 1.305 & 59.5 & 4.9 \\
\hline Buffalo, NY & 1.142 & 52.1 & 4.3 \\
\hline
\end{tabular}

\footnotetext{
${ }^{1}$ Includes Oakland, CA.

${ }^{2}$ Includes Fort Worth, TX.

${ }^{3}$ Includes Mesa, AZ.

${ }^{4}$ Includes St. Paul, MN.

${ }^{5}$ Includes St. Petersburg, FL.
} 
replacement gangs and collect the used ties. Two railroads that would disclose information about their tie replacement activities indicated that the contractors pay for the used ties. Further, one railroad had as many as 12 bidders for three separate contracts to recover used ties. The contractors must operate their own equipment for collecting, stockpiling, and hauling away the used ties. The number of quality ties that can be sold for reuse largely drives the ability of the contractor to economically operate. Wholesale prices for good used ties range from $\$ 5$ to $\$ 10$ per tie.

RailWorks Wood Waste Energy and Tampa International are two major used-tie contractors. They were contacted to discuss markets for their used ties and get information on tie-processing costs $(24,25)$. RailWorks handles approximately $60 \%$ of the entire Class I used tie market, while Tampa International handles $95 \%$ of used CSX ties. Both companies indicated that their primary market (by volume) is chipped-tie fuel, while the secondary market consists of good used ties for landscaping (typically sold to garden centers and building supply companies).

RailWorks indicated that within the Indiana area there is an "above-average" availability of used ties, which could open a new market of 1.0 to 1.5 million ties per year. RailWorks could also deliver whole ties rather than the customarily processed (hogged) ties. RailWorks currently operates tie-processing facilities in Minnesota, North Carolina, Mississippi, and Arkansas. These facilities are typically set up within a few miles of the fuel customer. RailWorks hauls whole ties to the chipping facilities via rail and prepares a nominal 3-inch minus mulchlike fuel using a hammermill. Depending upon the rail bed conditions where the used ties were removed, the tie moisture content may range from 10 to $50 \mathrm{wt} \%$. Tampa International operates similar facilities. Neither RailWorks nor Tampa International would disclose the production cost or selling price for a typical processedtie fuel. However, personnel at CMS Generation indicated that they are currently paying $\$ 2.50 /$ ton delivered for a 3-inch minus used-tie fuel (26).

The cost of further processing for use in an entrained-flow or similar conversion system may be cost-prohibitive. RailWorks indicated that it assisted the Tennessee Valley Authority in the development of a co-drying/hogging operation to produce a 3/16-inch minus product for cofiring in a suspension-fired boiler. The cost of production, at \$2/MMBtu, was too high. RailWorks believes that preparation costs would be similar for used-tie fuel sized for an entrained-flow gasifier.

\section{Urban Wood Waste}

\section{Indiana}

A resource assessment completed in 1995 indicated that the state of Indiana has a significant number of sawmills, furniture manufacturers, and pallet manufacturers that, in combination with tree-trimming and construction/demolition (C\&D) industries, generate large quantities of wood waste (27). At the time of the assessment, $66 \%$ of all UWW was being landfilled or given away. The study reviewed 11 metropolitan regions that encompassed $80 \%$ of Indiana's then 5.5 million people.

The assessment identified approximately 1650 generators of wood waste within the state. The generators were divided into five primary categories: secondary wood processors, pallet manufacturers/recyclers, urban tree and landscape residue generators, primary wood processors, and 
C\&D residue generators. Within the 11 regions, the generation of UWW was estimated to be $1,130,000 \mathrm{dry}$ tons/year, while the quantity available was approximately 743,000 dry tons/year.

The difference between generated and available UWW (i.e., 387,000 dry tons/year) represents the quantity that was 1) sold, 2) used captively by the generator for fuel, or 3) reused or recycled. Secondary wood processors sell sawdust, chips, and bark as mulch, commanding typically high prices ( $\$ 40 /$ dry ton at the time of the study). Pallet manufacturers/recyclers also sell or captively use a large fraction of the generated waste. Almost $80 \%$ of the UWW from primary wood processors is used to supply wood fiber for the local pulp/paper industry or is used captively as a fuel. Procurement of these UWW fractions as fuel would require paying prices substantially above those typically paid (\$/MMBtu) for traditional fossil fuels or petroleum coke.

The available UWW, 743,000 dry tons/year, was the amount landfilled or given away. This material represents potential fuel that could be obtained at zero or negative cost (excluding transportation). Urban tree and landscape residue plus C\&D residue comprised 55 and $23 \mathrm{wt} \%$, respectively, of all available UWW in Indiana. The reuse and recycle options are fewer for these two waste fractions, owing to their typically less desirable properties: variability in physical and chemical properties (as in the case of tree and landscape residue), the possible presence of hazardous materials, and the requirement for sorting (as in the case of demolition debris).

Table 5 presents the estimates for available UWW for the 11 regions. Within Region 8, which contains Terre Haute, the amount of UWW available is quite limited. At approximately 25,400 dry tons/year and assuming about $8000 \mathrm{Btu} / \mathrm{lb}$ (dry basis), this amount of UWW would supply $2.1 \%$ of the Wabash River gasifier thermal input. Approximately $78 \%$ of the UWW would comprise tree trimming/landscaping residue and C\&D debris. Although Region 8 has a substantial primary woodprocessing industry, $87 \%$ of the wood waste $(23,300$ dry tons/year) from this sector is recycled or reused.

Regions 1 and 3, which are substantially more populous than Region 8, could possibly provide $16 \%$ and $5.4 \%$, respectively, of the Wabash River gasifier thermal input. Again, the potential fuel load would largely comprise urban tree/landscape residue and C\&D debris. However, transport distances would become an issue, as the population centers for Regions 1 and 3 are 77 and 112 miles, respectively, from Terre Haute. Region 7, whose population center of Bloomington is only 57 miles from Terre Haute, has the potential to raise the available fuel load to about 70,600 dry tons/year, or $5.8 \%$ of the thermal input.

A similar analysis of UWW resource data for the neighboring state of Illinois was not performed, although the nearest major population centers (Decatur and Champaign-Urbana) are over 100 miles distant.

\section{Nationwide}

Wiltsee completed a study for the National Renewable Energy Laboratory in 1998 that analyzed the UWW resources of 30 randomly selected metropolitan U.S. areas with populations ranging from 84,000 to almost 4,000,000 people (28). The waste resources were classified as MSW 


\section{TABLE 5}

Estimate of Available Urban Wood Waste Within Indiana (weight in thousands of tons)

\begin{tabular}{llccc}
$\begin{array}{l}\text { Region } \\
\text { No. }\end{array}$ & \multicolumn{1}{c}{ Region Name } & $\begin{array}{c}\text { Population, } \\
\text { thousands }\end{array}$ & $\begin{array}{c}\text { UWW Available, } \\
\text { dry tons/year }\end{array}$ & $\begin{array}{c}\text { \% of Wabash River } \\
\text { Thermal Input }\end{array}$ \\
\hline 1 & Indianapolis & 1249 & 189.3 & 16.0 \\
2 & Fort Wayne & 364 & 76.5 & 6.4 \\
3 & Evansville & 339 & 63.9 & 5.4 \\
4 & Gary/Hammond & 712 & 84.4 & 7.1 \\
5 & South Bend/Elkhart & 403 & 95.0 & 8.0 \\
6 & Muncie/Anderson & 298 & 72.3 & 6.1 \\
7 & Bloomington & 267 & 45.2 & 3.8 \\
8 & Terre Haute & 161 & 25.4 & 2.1 \\
9 & Kokomo/Marion & 265 & 33.4 & 2.8 \\
10 & Richmond & 98 & 15.4 & 1.3 \\
11 & New Albany & 227 & 42.3 & 3.6 \\
\hline
\end{tabular}

wood, industrial wood, and C\&D wood. MSW wood is comprised of the nonrecoverable fraction of wood wastes disposed of with MSW (assumed in the study to be 3 to $5 \mathrm{wt} \%$ of MSW) and the wood waste diverted from the MSW stream. Wood diverted from the MSW stream included private tree trimmings and yard waste and the debris removed by utility and private tree services. Industrial wood included scrap and sawdust from pallet recycling, woodworking shops, and lumberyards. C\&D wood included wood debris from $\mathrm{C} \& \mathrm{D}$ activities as well as debris from land-clearing (i.e., preparation for new construction). These classifications were consistent with those used in the Indiana UWW resource assessment.

Based on the total quantities of wood waste in each of the three categories, the study developed weighted average coefficients for tons (with moisture included) of UWW generated per annum per person. The generation factors (wet tons/year/person) for MSW wood, industrial wood, and C\&D wood were estimated to be $0.209,0.048$, and 0.076 , respectively. The total UWW generation factor was 0.333 wet tons/year/person.

These coefficients were used here to predict the quantity of UWW generated by each of the 35 metropolitan areas of the United States with a population over 1 million people. The results are presented in Table 6 for each of the three UWW categories and for the total UWW. Values were converted to a dry tons/year basis assuming an average UWW solids content of $65 \mathrm{wt} \%$. The percentage of thermal input to a Wabash River-sized gasifier was estimated assuming a dry wood heating value of $8000 \mathrm{Btu} / \mathrm{lb}$. Approximately 120,000 dry tons/year of UWW would be required to provide $10 \%$ of the thermal input.

The results show that the quantity of generated wood may be substantial, with population centers over 5 million people theoretically being capable of providing $100 \%$ or more of the thermal input to a Wabash River-sized gasifier. However, the UWW available for use as fuel would be more limited. Although somewhat higher than the $66 \mathrm{wt} \%$ value identified in the Indiana resource 


\section{TABLE 6}

Estimated Generation of Urban Wood Waste for the 35 Largest U.S. Metropolitan Areas (weight in thousands of tons)

\begin{tabular}{|c|c|c|c|c|c|c|}
\hline City & $\begin{array}{l}\text { Population, } \\
\text { millions }\end{array}$ & $\begin{array}{c}\text { MSW } \\
\text { Wood, } \\
\text { dry } \\
\text { tons/year }\end{array}$ & $\begin{array}{l}\text { Industrial } \\
\text { Wood, } \\
\text { dry } \\
\text { tons/year }\end{array}$ & $\begin{array}{c}\text { C\&D } \\
\text { Wood, } \\
\text { dry } \\
\text { tons/year }\end{array}$ & $\begin{array}{c}\text { Total } \\
\text { UWW, } \\
\text { dry } \\
\text { tons/year }\end{array}$ & $\begin{array}{c}\% \text { of } \\
\text { Gasifier } \\
\text { Thermal } \\
\text { Input }\end{array}$ \\
\hline New York, NY & 15.000 & 2040 & 468 & 741 & 3250 & 274 \\
\hline Los Angeles, CA & 13.000 & 1770 & 406 & 642 & 2810 & 237 \\
\hline Chicago, IL & 8.008 & 1090 & 250 & 396 & 1730 & 146 \\
\hline San Francisco, $\mathrm{CA}^{1}$ & 6.188 & 841 & 193 & 306 & 1340 & 113 \\
\hline Philadelphia, PA & 5.999 & 815 & 187 & 296 & 1300 & 110 \\
\hline Dallas, $\mathrm{TX}^{2}$ & 4.910 & 667 & 153 & 243 & 1060 & 89.6 \\
\hline Washington, DC & 4.740 & 644 & 148 & 234 & 1030 & 86.5 \\
\hline Detroit, MI & 4.475 & 608 & 140 & 221 & 969 & 81.7 \\
\hline Houston, TX & 4.011 & 545 & 125 & 198 & 868 & 73.2 \\
\hline Atlanta, GA & 3.857 & 524 & 120 & 191 & 835 & 70.4 \\
\hline Miami, FL & 3.711 & 504 & 116 & 183 & 803 & 67.7 \\
\hline Boston, MA & 3.297 & 448 & 103 & 163 & 714 & 60.2 \\
\hline Seattle, WA & 3.260 & 443 & 102 & 161 & 706 & 59.5 \\
\hline Phoenix, $A Z^{3}$ & 3.014 & 409 & 94.0 & 149 & 652 & 55.0 \\
\hline Minneapolis, $\mathrm{MN}^{4}$ & 2.872 & 390 & 89.6 & 142 & 622 & 52.4 \\
\hline San Diego, CA & 2.821 & 383 & 88.0 & 139 & 611 & 51.5 \\
\hline St. Louis, MO & 2.569 & 349 & 80.2 & 127 & 556 & 46.9 \\
\hline Baltimore, MD & 2.491 & 338 & 77.7 & 123 & 539 & 45.5 \\
\hline Pittsburgh, PA & 2.331 & 317 & 72.7 & 115 & 505 & 42.5 \\
\hline Tampa, $\mathrm{FL}^{5}$ & 2.278 & 309 & 71.1 & 113 & 493 & 41.6 \\
\hline Cleveland, $\mathrm{OH}$ & 2.221 & 302 & 69.3 & 110 & 481 & 40.5 \\
\hline Denver, CO & 1.979 & 269 & 61.7 & 97.8 & 428 & 36.1 \\
\hline Portland, OR & 1.846 & 251 & 57.6 & 91.2 & 400 & 33.7 \\
\hline Kansas City, MO & 1.756 & 239 & 54.8 & 86.7 & 380 & 32.0 \\
\hline Cincinnati, $\mathrm{OH}$ & 1.628 & 221 & 50.8 & 80.4 & 352 & 29.7 \\
\hline Sacramento, CA & 1.585 & 215 & 49.5 & 78.3 & 343 & 28.9 \\
\hline San Antonio, TX & 1.565 & 213 & 48.8 & 77.3 & 339 & 28.6 \\
\hline Norfolk, VA & 1.563 & 212 & 48.8 & 77.2 & 338 & 28.5 \\
\hline Indianapolis, IN & 1.537 & 209 & 48.0 & 75.9 & 333 & 28.0 \\
\hline Orlando, FL & 1.535 & 209 & 47.9 & 75.8 & 332 & 28.0 \\
\hline Columbus, $\mathrm{OH}$ & 1.489 & 202 & 46.5 & 73.6 & 322 & 27.2 \\
\hline Milwaukee, WI & 1.462 & 199 & 45.6 & 72.2 & 316 & 26.7 \\
\hline Charlotte, $\mathrm{NC}$ & 1.417 & 192 & 44.2 & 70.0 & 307 & 25.9 \\
\hline New Orleans, LA & 1.305 & 177 & 40.7 & 64.5 & 282 & 23.8 \\
\hline Buffalo, NY & 1.142 & 155 & 35.6 & 56.4 & 247 & 20.8 \\
\hline
\end{tabular}

${ }^{1}$ Includes Oakland, CA.

${ }^{2}$ Includes Fort Worth, TX

${ }^{3}$ Includes Mesa, AZ.

${ }^{4}$ Includes St. Paul, MN.

${ }^{5}$ Includes St. Petersburg, FL. 
assessment, the Wiltsee study found that on average, the 30 metropolitan areas landfilled/incinerated or gave away as mulch about $73 \%$ of the UWW. Again, this material is comprised primarily of MSW wood and C\&D wood. However, opportunities may be available to provide between 5\% and 10\% of the thermal input using the higher-quality industrial wood. The Wiltsee report shows the production of industrial wood to be quite variable among the 30 municipalities studied, with the average disposition of industrial wood by landfilling/incineration or mulch being about $33 \%$.

It should be noted that UWW actually available for use as a fuel within a specific metropolitan area or region will be dictated by landfill tipping fees, regulations concerning dumping/burning, public policy/attitude with regard to reuse and recycling, and the proximity to and competition from other large wood waste users.

\section{Municipal Solid Waste}

\section{Indiana}

Data for the generation and disposal of MSW, C\&D debris, and other solid waste within Indiana were obtained from the Indiana Department of Environmental Management 1999 summary data report on the operation of solid waste facilities (29). Solid waste facilities include landfills, transfer stations, and incinerators. The solid waste data were presented in terms of both the county of origin and the facility of disposition.

To determine the potential availability of MSW for utilization by the Wabash River gasifier, the quantity of MSW generated within Vigo County (which contains Terre Haute) and within adjacent Indiana counties was determined. The results are presented in Table 7 for Vigo County and 15 other counties with borders that are within approximately 50 straight-line miles of Terre Haute. The values for MSW represent material that is destined for landfilling or incineration and has had recyclables already removed by curbside or transfer station recovery. Assuming a heating value of $4500 \mathrm{Btu} / \mathrm{lb}$ for the MSW, the percentage of thermal input to the Wabash River gasifier was estimated for each county of MSW origin.

Approximately 210,000 tons/year of unsorted MSW would be required to achieve a target thermal input value of $10 \%$. Among the 16 counties, the largest quantity of MSW, 160,000 tons/year, is generated in Vigo County. Presently, 95\% of Vigo County MSW stays within the county, being disposed of at a landfill near Terre Haute. This quantity of MSW is alone sufficient to provide 7.6\% of the gasifier thermal input. Monroe County could theoretically supply an additional $4.6 \%$ of the thermal input for a total of $12.2 \%$. The remaining 14 counties could more than double the available MSW to 568,000 tons/year, achieving a thermal input of almost $27 \%$.

The tipping fee charged by Wabash River would dictate the MSW that can become available for use as a gasifier fuel at Wabash River. The proximity to the current landfill would suggest high potential to compete for the MSW resource within Vigo County. The ability to attract MSW from surrounding counties (and communities) would further be influenced by the combined transportation and tipping fees currently being paid by surrounding cities or solid waste management districts. 


\section{TABLE 7}

MSW Resource Available Within Indiana Counties Adjacent to Terre Haute

\begin{tabular}{lccc}
\hline County & $\begin{array}{c}\text { MSW, } \\
\text { ton/year }\end{array}$ & $\begin{array}{c}\text { \% of Thermal Input } \\
\text { to Wabash River } \\
\text { Gasifier }\end{array}$ & $\begin{array}{c}\text { Cumulative \% of } \\
\text { Thermal Input }\end{array}$ \\
\hline Vigo & 160,250 & 7.6 & 7.6 \\
Monroe & 97,190 & 4.6 & 12.2 \\
Montgomery & 73,630 & 3.5 & 15.7 \\
Hendricks & 67,950 & 3.2 & 18.9 \\
Morgan & 39,410 & 1.9 & 20.8 \\
Putnam & 24,690 & 1.2 & 22.0 \\
Clay & 23,930 & 1.1 & 23.1 \\
Knox & 17,420 & 0.8 & 23.9 \\
Greene & 16,290 & 0.8 & 24.7 \\
Vermillion & 12,530 & 0.6 & 25.3 \\
Sullivan & 12,410 & 0.6 & 25.9 \\
Parke & 7370 & 0.3 & 26.2 \\
Owen & 7200 & 0.3 & 26.6 \\
Daviess & 6100 & 0.3 & 26.9 \\
Warren & 1290 & 0.1 & 26.9 \\
Fountain & 550 & 0.0 & 27.0 \\
\hline
\end{tabular}

\section{Illinois}

Data for the generation and disposal of MSW within Illinois were obtained from the Illinois Environmental Protection Agency (EPA) 1998 Annual Report on Nonhazardous Solid Waste Management and Landfill Capacity (30). Subsequent to the initial data review, an annual report has been published by the Illinois EPA covering the year 1999 (31).

Similar to the exercise with Indiana MSW data, the potential availability of MSW within adjacent Illinois for utilization by the Wabash River gasifier was determined. The results are presented in Table 8 for 11 Illinois counties whose county lines are within approximately 50 straightline miles of Terre Haute. Again, the MSW quantities represent material that remains after recyclables recovery and is destined for landfilling or incineration. Assuming a heating value of 4500 $\mathrm{Btu} / \mathrm{lb}$ for the MSW, the percentage of thermal input to the Wabash River gasifier was estimated for each county of MSW origin.

Among the 11 counties, the largest quantity of MSW, 150,600 tons/year, is generated in Champaign County. This quantity of MSW is alone sufficient to provide about $7 \%$ of the gasifier thermal input. However, the majority of this MSW would be from Champaign-Urbana, which is about 100 highway miles from Terre Haute. The remaining 10 counties could provide an additional 240,000 tons/year, or slightly more than $11 \%$ of the thermal input. 


\section{TABLE 8}

MSW Resource Available Within Illinois Counties Adjacent to Terre Haute

\begin{tabular}{lrcc}
\hline County & $\begin{array}{r}\text { MSW, } \\
\text { ton/yr }\end{array}$ & $\begin{array}{c}\text { \% of Thermal Input } \\
\text { to Wabash River } \\
\text { Gasifier }\end{array}$ & $\begin{array}{c}\text { Cumulative \% of } \\
\text { Thermal Input }\end{array}$ \\
\hline Champaign & 150,620 & 7.1 & 7.1 \\
Vermilion & 73,410 & 3.5 & 10.6 \\
Coles & 63,290 & 3.0 & 13.6 \\
Edgar & 21,250 & 1.0 & 14.6 \\
Clark & 17,580 & 0.8 & 15.4 \\
Crawford & 13,450 & 0.6 & 16.1 \\
Richland & 12,320 & 0.6 & 16.6 \\
Douglas & 12,080 & 0.6 & 17.2 \\
Cumberland & 11,830 & 0.6 & 17.8 \\
Lawrence & 11,420 & 0.5 & 18.3 \\
Jasper & 3320 & 0.2 & 18.5 \\
\hline
\end{tabular}

\section{Nationwide}

Data for the nationwide generation and/or disposal of MSW appear to be quite varied. U.S. EPA data for 1998 indicate that approximately 0.8 tons of MSW as generated per person per year, with $28 \%$ being diverted by recycling or composting (32). The remaining fraction was slated for landfilling or incineration. The generation value was based on 220 million tons of MSW generated and a population of 267.6 million people. This equates to an actual disposal rate of 0.592 tons/person/year. Biocycle, a solid waste industry publication, indicated that in the year 1999 after a $31.5 \%$ recycling rate, almost 270 million tons of municipal waste was disposed of - a rate essentially equivalent to 0.979 tons/person/year (33).

Available data indicate that between $15 \%$ and $20 \%$ of this waste headed for disposal is incinerated (without energy recovery) or used for fuel in a waste-to-energy (WTE) facility. An estimate for MSW headed for landfilling, assuming a 20\% incineration/WTE usage rate, would then be about 0.783 tons/person/year. In comparison, the landfilling rates in the states of Indiana and Illinois are about 0.87 and 1.0 tons/person/year, respectively. The higher landfilling rates in these two states relative to the nationwide average are partly due to their low incineration/WTE usage rates-less than $4 \%$ for both states.

The estimated MSW landfilling rate of 0.783 tons/person/year was used to predict the quantity of MSW generated by each of the 35 metropolitan areas of the United States with a population over 1 million people. The results are presented in Table 9. Assuming a heating value of $4500 \mathrm{Btu} / \mathrm{lb}$ for the MSW, the percentage of thermal input to the Wabash River gasifier was estimated for each city of MSW origin. The results show that MSW would provide two times the thermal input relative to UWW, the next most available fuel resource. The actual MSW available in each of these cities may be substantially higher or lower than these values, as some of these metropolitan areas, for example, 


\section{TABLE 9}

Estimated Generation of Municipal Solid Waste for the 35 Largest U.S. Metropolitan Areas (weights in thousands of tons)

\begin{tabular}{|c|c|c|c|}
\hline City & $\begin{array}{l}\text { Population, } \\
\text { millions }\end{array}$ & $\begin{array}{c}\text { Municipal Solid Waste, } \\
\text { tons/year }\end{array}$ & $\begin{array}{l}\% \text { of Gasifier } \\
\text { Thermal Input }\end{array}$ \\
\hline New York, NY & 15.000 & 11,700 & 557 \\
\hline Los Angeles, CA & 13.000 & 10,200 & 483 \\
\hline Chicago, IL & 8.008 & 6270 & 297 \\
\hline San Francisco, $\mathrm{CA}^{1}$ & 6.188 & 4850 & 230 \\
\hline Philadelphia, PA & 5.999 & 4700 & 223 \\
\hline Dallas, $\mathrm{TX}^{2}$ & 4.910 & 3840 & 182 \\
\hline Washington, DC & 4.740 & 3710 & 176 \\
\hline Detroit, MI & 4.475 & 3500 & 166 \\
\hline Houston, TX & 4.011 & 3140 & 149 \\
\hline Atlanta, GA & 3.857 & 3020 & 143 \\
\hline Miami, FL & 3.711 & 2910 & 138 \\
\hline Boston, MA & 3.297 & 2580 & 122 \\
\hline Seattle, WA & 3.260 & 2550 & 121 \\
\hline Phoenix, $A Z^{3}$ & 3.014 & 2360 & 112 \\
\hline Minneapolis, $\mathrm{MN}^{4}$ & 2.872 & 2250 & 107 \\
\hline San Diego, CA & 2.821 & 2210 & 105 \\
\hline St. Louis, MO & 2.569 & 2010 & 95.4 \\
\hline Baltimore, MD & 2.491 & 1950 & 92.5 \\
\hline Pittsburgh, PA & 2.331 & 1830 & 86.5 \\
\hline Tampa, FL $^{5}$ & 2.278 & 1780 & 84.6 \\
\hline Cleveland, $\mathrm{OH}$ & 2.221 & 1740 & 82.5 \\
\hline Denver, CO & 1.979 & 1550 & 73.5 \\
\hline Portland, OR & 1.846 & 1450 & 68.5 \\
\hline Kansas City, MO & 1.756 & 1370 & 65.2 \\
\hline Cincinnati, $\mathrm{OH}$ & 1.628 & 1270 & 60.4 \\
\hline Sacramento, CA & 1.585 & 1240 & 58.8 \\
\hline San Antonio, TX & 1.565 & 1230 & 58.1 \\
\hline Norfolk, VA & 1.563 & 1220 & 58.0 \\
\hline Indianapolis, IN & 1.537 & 1200 & 57.1 \\
\hline Orlando, FL & 1.535 & 1200 & 57.0 \\
\hline Columbus, $\mathrm{OH}$ & 1.489 & 1170 & 55.3 \\
\hline Milwaukee, WI & 1.462 & 1140 & 54.3 \\
\hline Charlotte, NC & 1.417 & 1110 & 52.6 \\
\hline New Orleans, LA & 1.305 & 1020 & 48.5 \\
\hline Buffalo, NY & 1.142 & 894 & 42.4 \\
\hline $\begin{array}{l}{ }^{1} \text { Includes Oakland, C } \\
{ }^{2} \text { Includes Fort Worth, } \\
{ }^{3} \text { Includes Mesa, AZ. } \\
{ }^{4} \text { Includes St. Paul, M } \\
{ }^{5} \text { Includes St. Petersbu }\end{array}$ & & & \\
\hline
\end{tabular}


Minneapolis and St. Paul in Minnesota and Indianapolis, Indiana, have WTE facilities that consume a significant fraction of the available MSW.

\section{Waste Tires/Tire-Derived Fuel}

\section{Indiana}

Based on the Indiana 1999 State of the Environment Report (34), Indiana generated about 5.5 million additional waste tires in 1999, or about 1 tire per person. At about 15,000 Btu/lb and $20 \mathrm{lb}$ per tire (passenger), all of the used tires produced yearly in Indiana would only provide 8.7\% of the fuel input to the Wabash River gasifier. In 1997, approximately 18.5 million scrap tires remained in illegal dumps within Indiana, with this number being reduced by about 1 million tires per year through state-funded cleanup efforts. The state has two large tire dumps containing over 1 million tires each, but these dumps are located between 140 and 170 miles distant in Dearborn and Kosciusko counties. Several dozen tire dumps are located within about 50 straight-line miles of Terre Haute, but these are smaller, containing several hundred thousand or fewer tires.

The potential availability of tire-derived fuel (TDF) was discussed with the president of Auburndale Recycling Center (35). Auburndale has tire-processing facilities in Wisconsin but also collects tires from Indiana and four other Great Lakes and midwestern states (36). This company could immediately provide 50,000 tons of 2 -inch $\times 2$-inch TDF. This product would sell for about $\$ 20 /$ ton; a $3 / 4$-inch to 1.25 -inch TDF is sold to a local utility for $\$ 27 /$ ton delivered. The heat content can range from 12,500 to $16,500 \mathrm{Btu} / \mathrm{lb}$, depending upon the level of metal separation. The Auburndale company president indicated that processing a tire completely to a $3 / 4$-inch minus size would be cost-prohibitive for TDF applications.

\section{Illinois}

A similar search of scrap tire availability was not performed for the state of Illinois.

\section{Nationwide}

According to Waste Age, 270 million scrap tires were generated in 1998 within the United States, essentially one for each U.S. inhabitant (37). Through 1998, 500 million tires remained in 2800 stockpiles, legal and illegal. In 1997, it was estimated that over $70 \%$ of scrap tires were reused, with TDF being the largest secondary market. The remaining $30 \%$ of scrap tires, or about 80 million tires/year, represents a significant resource for use as a fuel but this would be a widely dispersed commodity.

The cost for producing a fuel for use in an entrained-flow gasifier appears to be unfavorable. The typical market prices for tire-derived materials indicate that tire chips, both 1-inch and 2-inch, used as fuel range from $\$ 10$ to $\$ 45$ per ton (38). Further, market prices for $1 / 4$-inch and 3/8-inch material range from $\$ 200$ to $\$ 220$ per ton. 


\section{FEED SYSTEM DEVELOPMENT}

\section{Estimation of Terminal Velocities for Feedstocks}

Estimates were made for the maximum particle size that could be entrained at conditions within the E-Gas gasifier operated at Wabash River. The maximum particle size would dictate the method(s) and economics for processing different biomass to sizes suitable for feeding to the gasifier.

The estimated entrainment velocity was made by calculating the terminal free-fall velocity of a particle of assumed diameter and sphericity. The maximum particle size would be that which produces a terminal velocity less than or equal to the gas velocity within the second stage of the gasifier.

The method proposed by Haider and Levenspiel (39) was used to calculate terminal velocity. Equations 1-3, shown below, indicate the sequence for first calculating a dimensionless particle size, then using the dimensionless particle size to calculate a dimensionless terminal velocity and, finally, converting the dimensionless terminal velocity to an actual terminal velocity. The equations are applicable to a wide range of particle shapes, including spherical, cubical, cylindrical, disklike, or irregular; very flat shapes with a width 10 times that of the height or thickness are not covered.

$$
\begin{gathered}
d_{p}^{*}=d_{p}\left[\frac{\rho_{g}\left(\rho_{s}-\rho_{g}\right) g}{\mu^{2}}\right]^{1 / 3} \\
u_{t}^{*}=\left[\frac{18}{\left(d_{p}^{*}\right)^{2}}+\frac{2.335-1.744 \Phi_{s}}{\left(d_{p}^{*}\right)^{0.5}}\right]^{-1} \text { for } 0.5<\Phi_{s}<1 \\
u_{t}=u_{t}^{*}\left[\frac{\mu\left(\rho_{s}-\rho_{g}\right) g}{\rho_{g}^{2}}\right]^{1 / 3}
\end{gathered}
$$

Parameters for the calculations are described in Appendix A. The gas viscosity was obtained from published data (40) and was based on operating conditions provided by Global Energy. Calculations were performed over two ranges of particle specific densities: 30 to $45 \mathrm{lb} / \mathrm{ft}^{3}$ and 60 to $90 \mathrm{lb} / \mathrm{ft}^{3}$. The former range represents that typical for wood and agricultural residues, while the latter 
range represents densities typical for plastic, rubber, and leather (41). The density for sewage sludge was measured to be approximately $68 \mathrm{lb} / \mathrm{ft}^{3}$, thus falling in the latter range.

\section{Drop-Tube Furnace Testing}

Estimations of terminal velocities for various biomass feedstocks indicate that the maximum particle size of sewage sludge for entrainment will be no larger than about 0.1 to 0.2 inches at the known operating conditions of the gasifier. In support of the determination of proper sewage sludge size for injection into the Wabash River gasifier, it was hypothesized that the presence of large quantities of moisture within the sewage sludge may aid in its dispersion and rapid conversion. It was thought that exposure to the high-temperature gas (approximately $2500^{\circ} \mathrm{F}$ ) of the second stage and the large amount of radiant energy from the refractory lining may cause the bound moisture to rapidly expand and vaporize. The expansion and vaporization would ideally be violent enough to cause the sludge particles to disintegrate into many smaller, more easily entrained particles. Therefore, the dispersion requirements of the sludge-feeding device would not be as rigorous.

To test the ability of the sewage sludge to violently disintegrate, the EERC's optical drop- tube furnace was used as the radiant heat source. The furnace, shown schematically in Figure 1, was reconfigured by removing the injector (for pulverized fuels), flow straightener, quench probe, and collection filter. The injector was replaced with a dairy flange cap. The quench probe and filter were replaced with a stainless steel collection pot lined with high-temperature glass insulation. The insulation functioned to provide a cushion for dropped sludge pellets. With the preheat furnace, hightemperature furnaces, and optical-zone furnace, the heated length measures 6 feet.

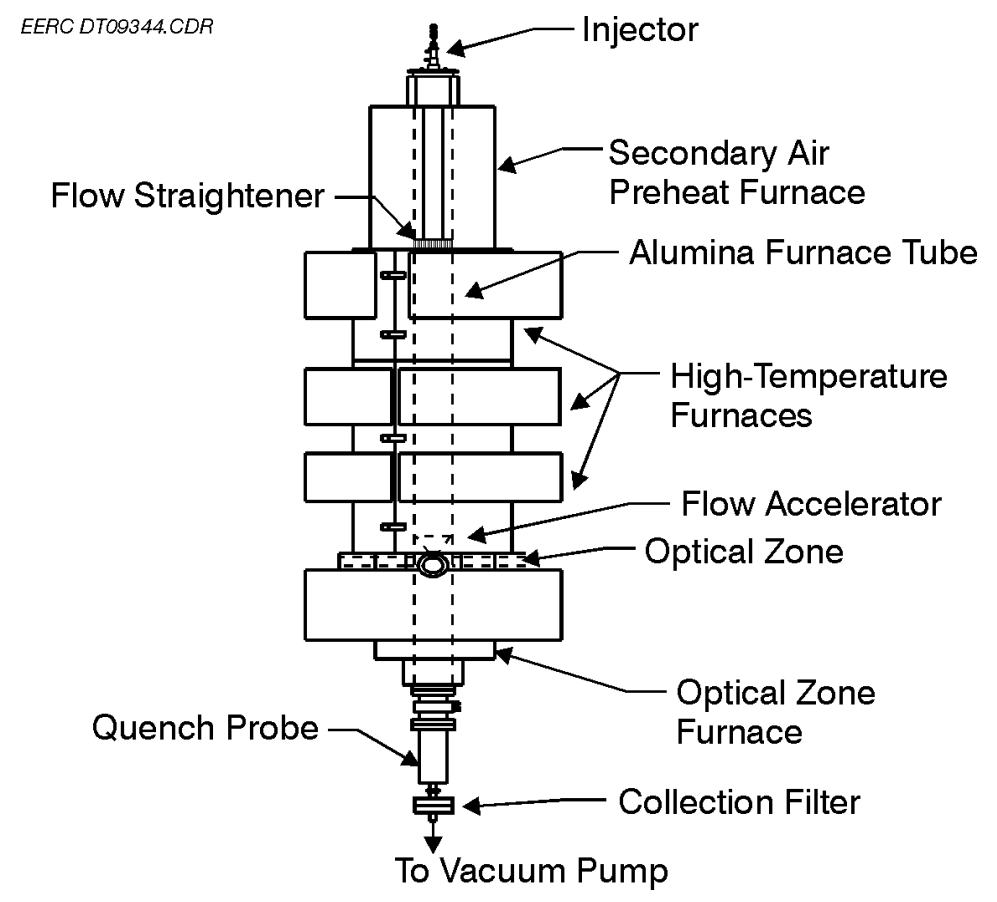

Figure 1. EERC optical drop-tube furnace. 
For all tests, the preheat furnace was maintained at $1000^{\circ} \mathrm{C}$ (the maximum for the heater), and the remaining furnaces were maintained at approximately $1400^{\circ} \mathrm{C}$. This setting was sufficient to achieve a maximum furnace temperature of $1370^{\circ} \mathrm{C}\left(2500^{\circ} \mathrm{F}\right)$ as measured by a thermocouple positioned within the furnace. Nitrogen at approximately $3 \mathrm{ft}^{3} /$ hour was injected from the top to provide an inert atmosphere within the furnace and inhibit sludge combustion.

Undigested sewage sludge from Indianapolis, Indiana, was used in all tests. Pieces of sludge were rolled by hand into spheres of $1 / 8$ inch to $1 / 4$-inch. During a test, a sludge sphere was weighed and then dropped into the furnace after lifting the removable dairy fitting cap. The collection pot at the bottom was then removed to inspect the condition of the spherical sludge. Two tests with spherical sludge showed that the pellets stayed intact and did not exhibit a tendency to violently disintegrate. Rather, upon repeated drops, the pellets remained spherical in shape but shrank in size and mass. For one test, the pellet was reduced in mass by only $50 \mathrm{wt} \%$ after 12 drops through the furnace. A similar test was performed with a button-shaped pellet of 5/8-inch diameter and $1 / 8$-inch thickness. The button-shaped pellet remained intact after losing $49 \mathrm{wt} \%$ of its mass through 13 drops.

Several tests were performed by introducing spherical pellets on a ceramic tube into the heated zone through the optical ports. A video camera was used to view and record the effect on the pellets during an approximately 3 -second hold time in the $1370^{\circ} \mathrm{C}$ zone. Several repeat tests with new pellets showed that in real time the pellets would just shrink in size without falling apart. Measurements with one pellet showed that the mass loss was approximately proportional to the reduction in pellet volume. For all tests performed, the drying actually functioned to produce a relatively firm pellet.

\section{Sewage Sludge Feeding Across Pressure Boundary}

Feed system developments are presently concentrating on dewatered sewage sludges with solid contents in the range of 23 to $25 \mathrm{wt} \%$, a very common product in the municipal wastewater treatment sector. As Global Energy has indicated that economic and operational penalties associated with the high-moisture content sludge would be minimal, a system that can feed this sludge with no preprocessing could ideally result in near-term success for commercial application.

For these dewatered sludges, pumping has been selected as a logical method for breaching the pressure boundary (410 psig) of the Wabash River gasifier. Several commercial pump options are available that would seem to provide near-term applicability for feeding viscous, nonflowable sludges into a pressurized atmosphere. Pump configurations included conventional piston and progressive cavity pumps and a novel pump utilizing nonimpingement boundary layer and viscous drag. Pump types and manufacturers are listed in Table 10.

Pumps offered by Schwing America (42) and Putzmeister (43) are based on concrete pump designs reconfigured for the pipeline transport of highly dewatered municipal and industrial sludges. Typical applications include pumping dewatered sludges to haulage trucks or incinerators located several hundred feet from the sludge-dewatering facility. These pumps can achieve pumping pressures up to 2000 psig and capacities of 500 gallons per minute (gpm); however, these values are not mutually attainable. Both manufacturers claim the ability to pump municipal sludges with solids 
TABLE 10

Pump Manufacturers and Pump Type

\begin{tabular}{lc}
\hline Manufacturer & Type \\
\hline Schwing America & Double piston \\
Putzmeister & Double piston \\
Moyno & Progressive cavity \\
Discflo & Nonimpingement \\
\hline
\end{tabular}

contents up to $40 \mathrm{wt} \%$. These sludge pumps are equipped with twin-screw, high-torque feeders that are designed to maintain high pump-filling efficiency by forcing the highly viscous sludge into the piston chambers.

Both piston pump manufacturers offer commercial pumps that have a method of backflow control, typically hydraulically actuated seat or poppet valves. Each piston chamber has a seat valve for the inlet and outlet that opens and closes with each filling and pumping cycle. This feature would appear to be desirable from the standpoint of providing a positive method for preventing uncontrolled backflow of gasifier contents upon suspension of sludge feeding.

Moyno has recently entered the dewatered sludge-pumping market with its HS 2000 series of progressive cavity pumps (44). As a consequence, the demonstrated operating history for Moyno pumps with highly dewatered municipal sludge is minimal. As with the piston pumps, the Moyno HS series is equipped with twin-screw feeders to achieve pump filling. These pumps have capacities up to $2500 \mathrm{gpm}$ but maximum pumping pressures of $1000 \mathrm{psi}$. The Moyno pump offers nonpulsating flow; piston pumps have a slight pulsation between piston strokes. A potential drawback to the Moyno pump is that the pump stator is constructed of an elastomer that has a temperature limit of $350^{\circ} \mathrm{F}$. This elastomer would be damaged if the sludge were preheated to temperatures above $350^{\circ} \mathrm{F}$. Further, the pump is not equipped with a positive means of backflow prevention.

The novel pump marketed by Discflo (45) does not rely on centrifugal force or a screw, lobe, or impeller to move the liquid to be pumped. The Discflo pump relies on the boundary layer and viscous drag forces created between one or more rotating disks and a high-viscosity fluid to achieve pumping. This nonimpingement design is touted to derive its advantage over conventional pumps largely through its greatly reduced maintenance and parts replacement costs. Application of Discflo pumps in the municipal sewage sludge area is minimal, however.

Each of these pump manufacturers was contacted to ascertain 1) background information on the functioning and application of pumps, 2) a sample agreement and estimated cost for leasing a demonstration pump for testing at the EERC, and 3 ) capital and estimated operating costs (including maintenance) for a commercial system designed to provide $10 \%$ of the thermal input to the Wabash River gasifier.

The degree of interest and the ability to provide a lease pump varied considerably among manufacturers. At the time of inquiry, Putzmeister did not have a demonstration pump equipped with 
the seat or poppet valves. Discflo was equally encumbered by its inability to release a pump for testing and its lack of a pump model that could achieve operating pressures above $410 \mathrm{psig}$. Its pump was also not equipped with a twin-screw feeder. Moyno, after repeated inquiries, did not produce an affirmative response to the ability to lease a pump.

The capital and operating cost data were used to perform a present value analysis based on a 20-year life and a 5\% discount rate. The analysis spreadsheet is shown in Figure 2. The Discflo pump, although having an installed cost of less than half of the other pumps, was severely disadvantaged by a high horsepower requirement and, consequently, a high annual electrical operating cost. The Moyno pump appeared to have the most favorable present value, although the vendor quote for horsepower requirement was based on a fluid with a viscosity of 1 centipoise.

As part of proposed demonstrations at the EERC, the Schwing America pump with poppet valves has been selected for testing. A schematic diagram of a pump with twin-screw feed auger is presented in Figure 3. Proposed test activities with the pump are discussed later.

Subsequent to the discussions with commercial sludge pump manufacturers, it was determined that an EERC associate owns a Morgen Mustang (46) concrete pump that works on the same principal as the Schwing and Putzmeister sludge pumps. A picture of a similar pump is shown in Figure 4 and a cutaway schematic is shown in Figure 5. This diesel-operated pump uses dual pistons to deliver up to $40 \mathrm{yd}^{3} / \mathrm{hr}$ of concrete. The trailer-mounted concrete pump differs from the sludge pumps in that it is not equipped with poppet valves for positive backflow prevention nor is it equipped with a twin-screw auger for positive feeding of sludge to the pistons. This pump uses a "swing valve" that switches between piston chambers. A floating seal ring on the swing valve maintains a seal against the wear plate around the piston chamber outlets.

\section{Dispersion/Injection of Sewage Sludge}

After breaching the pressure boundary, it is envisioned that the sludge will need to be dispersed at a sufficiently small particle size to assure rapid reactivity and, minimally, entrainment. Three methods of injection/dispersion of sewage sludge into the Wabash River entrained-flow gasifier have been considered to date: pneumatic injection through a nozzle, screw-feeding with assistance by pneumatic dispersion, and mechanical feeding/dispersion.

\section{Mechanical Feeding/Dispersion}

Concepts for mechanical feeding/dispersion have included 1) extrusion through a die followed by cutting of sludge extrudate with a high-speed rotational knife and 2) a modified agricultural manure/sludge spreader using high-rotational-speed hammers or impellers to "project" sludge. The principal drawback to these systems would be the short operating life and low reliability of rotating parts exposed to the high-temperature $\left(2500^{\circ} \mathrm{F}\right)$ and slagging atmosphere at the injection point. Further, preliminary estimates indicate that rotational speeds for an impeller or hammers in a spreader-type system would be excessive (several thousand rpm). The mechanical feeding/dispersion concept has not been pursued further. 


\begin{tabular}{|c|c|c|c|c|}
\hline Company: & Discflo & Putzmeister & Schwing & Moyno HS \\
\hline Pump Type & Disk & Dual-piston & Dual-piston & Progressive cavity \\
\hline Viscocity, cP & 100,000 & 100,000 & 100,000 & 100,000 \\
\hline Sludge Solids, wt $\%$ & 21.4 & 21.4 & 21.4 & 23 \\
\hline Head, psig & 514 & 514 & 514 & 514 \\
\hline Flow, gpm & 170 & 170 & 170 & 170 \\
\hline $\mathrm{Hp}$ & 600 & 150 & 200 & 100 \\
\hline Cost & $\$ 74,525$ & $\$ 149,450$ & $\$ 163,480$ & $\$ 59,739$ \\
\hline Cost/hp & $\$ 124$ & $\$ 996$ & $\$ 817$ & $\$ 597$ \\
\hline Cost/Flow & $\$ 438$ & $\$ 879$ & $\$ 962$ & $\$ 351$ \\
\hline Hp/Flow & 3.5 & 0.9 & 1.2 & 0.6 \\
\hline Life & $\begin{array}{l}5 \text { times greater than } \\
\text { centrifugal }\end{array}$ & Pistons $(5000 \mathrm{hr})$ & Pistons (5000 hr) & $\begin{array}{l}\text { Rotor every } 2 \text { years, } \\
\text { stator every year }\end{array}$ \\
\hline Annual Parts Cost & $\$ 2,500$ & $\$ 27,089$ & $\$ 27,089$ & $\$ 28,400$ \\
\hline Major Repl. Part & Rotor & $\begin{array}{l}\text { Main drive } \\
\text { cylinders }\end{array}$ & $\begin{array}{l}\text { Main drive } \\
\text { cylinders }\end{array}$ & Rotor, stator \\
\hline Annual Labor Time & 5 hours & 80 hours & 80 hours & 16 \\
\hline Annual Labor Cost & $\$ 500$ & $\$ 8,000$ & $\$ 8,000$ & $\$ 1,600$ \\
\hline Annual Operating Time & 7884 & 7884 & 7884 & 7884 \\
\hline $\begin{array}{l}\text { Annual Operating Cost, } \\
\$ 0.07 / \mathrm{kWh}\end{array}$ & $\$ 248,346$ & $\$ 62,087$ & $\$ 82,782$ & $\$ 41,391$ \\
\hline Total Annual Operating & $\$ 251,346$ & $\$ 97,176$ & $\$ 117,871$ & $\$ 71,391$ \\
\hline Auger Feed Pump & $\$ 19,000$ & $\$ 46,550$ & $\$ 50,920$ & \\
\hline Control Panel & & $\$ 44,100$ & $\$ 48,240$ & \\
\hline Power Unit & & $\$ 56,350$ & $\$ 61,640$ & \\
\hline Misc. Equip. & & $\$ 4,900$ & $\$ 5,360$ & $\$ 128,083$ \\
\hline Total Package Costs & $\$ 93,525$ & $\$ 245,000$ & $\$ 268,000$ & $\$ 187,822$ \\
\hline Notes & $\begin{array}{l}\text { Discflo seemed to think } \\
\text { we would only need a } \\
600-\mathrm{hp} \mathrm{pump} \text {. The } \\
\text { results at } 100,000 \mathrm{cp} \\
\text { indicate a 900-hp } \\
\text { requirement. }\end{array}$ & $\begin{array}{l}\text { Pump price only } \\
\text { includes the hydraulic } \\
\text { power unit and the } \\
\text { pump. }\end{array}$ & $\begin{array}{l}\text { Pump price only } \\
\text { includes the hydraulic } \\
\text { power unit and the } \\
\text { pump. }\end{array}$ & $\begin{array}{l}\text { Pump price only } \\
\text { includes the pump, } \\
\text { drive, and base; misc. } \\
\text { equipment includes } \\
\text { twin-screw feed with } \\
\text { drive, suction/discharge } \\
\text { pressure sensors, and } \\
\text { SRI metering station. }\end{array}$ \\
\hline Life, years & 20 & 20 & 20 & 20 \\
\hline Int Rate & $5 \%$ & $5 \%$ & $5 \%$ & $5 \%$ \\
\hline Present Value & $(\$ 3,190,603)$ & $(\$ 1,363,684)$ & $(\$ 1,635,927)$ & $(\$ 1,006,724)$ \\
\hline
\end{tabular}

Figure 2. Present value analysis for pumps reviewed for sewage sludge pumping into pressurized atmosphere.

\section{Screw Feeding}

Screw feeding was considered because the auger flights would theoretically provide an initial means of delumping the pumped sludge, and depending upon the degree of pulsation by a piston pump, the screws would help level out the sludge flow rate. This concept would rely upon a directed stream of high-pressure gas from a dispersion nozzle to further size-reduce and convey the sludge into the flowing gas stream of the gasifier.

As part of proposed demonstrations at the EERC, a twin-screw auger that would be coupled with the Schwing piston pump was designed. The system was sized based on an estimated maximum 


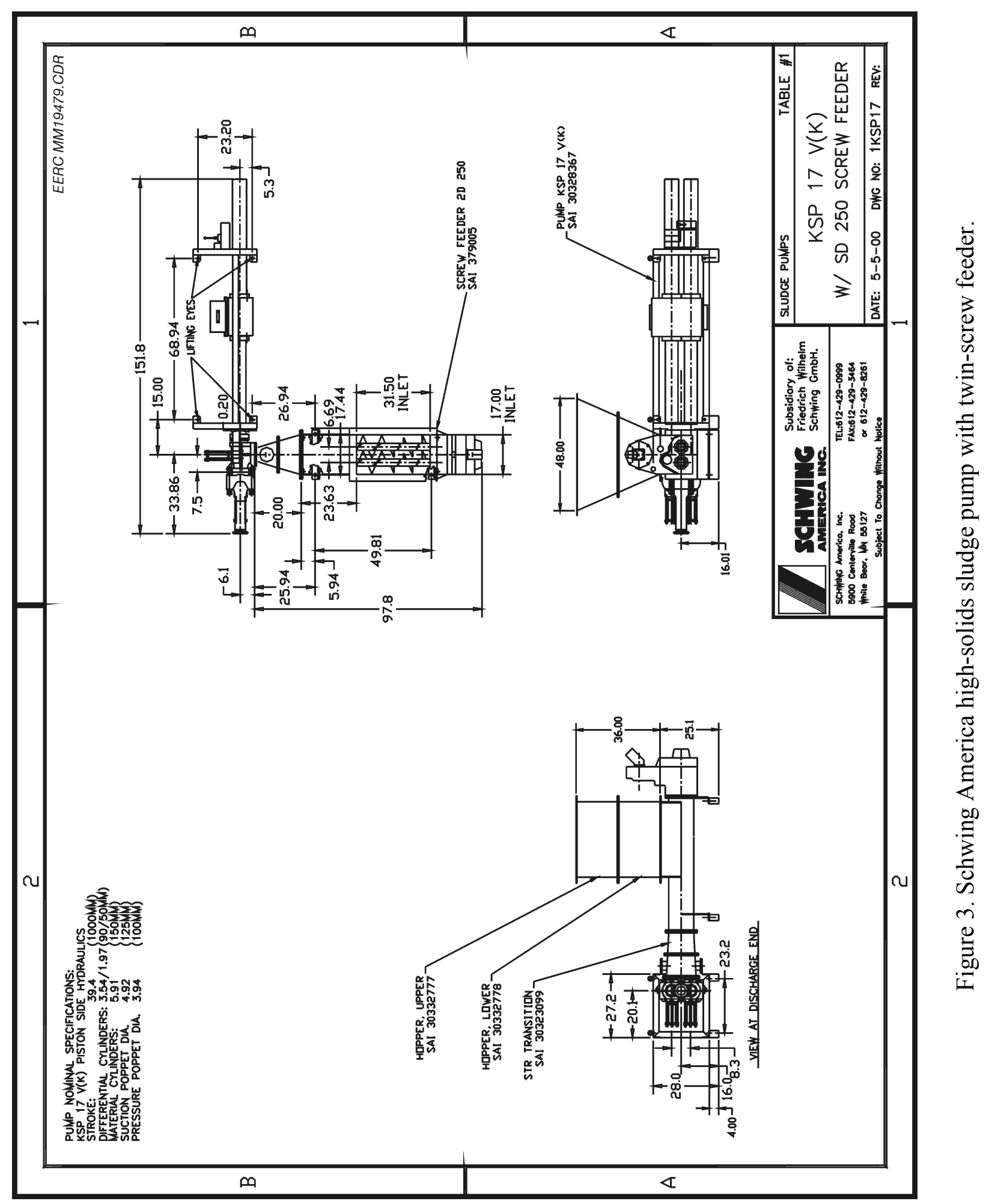




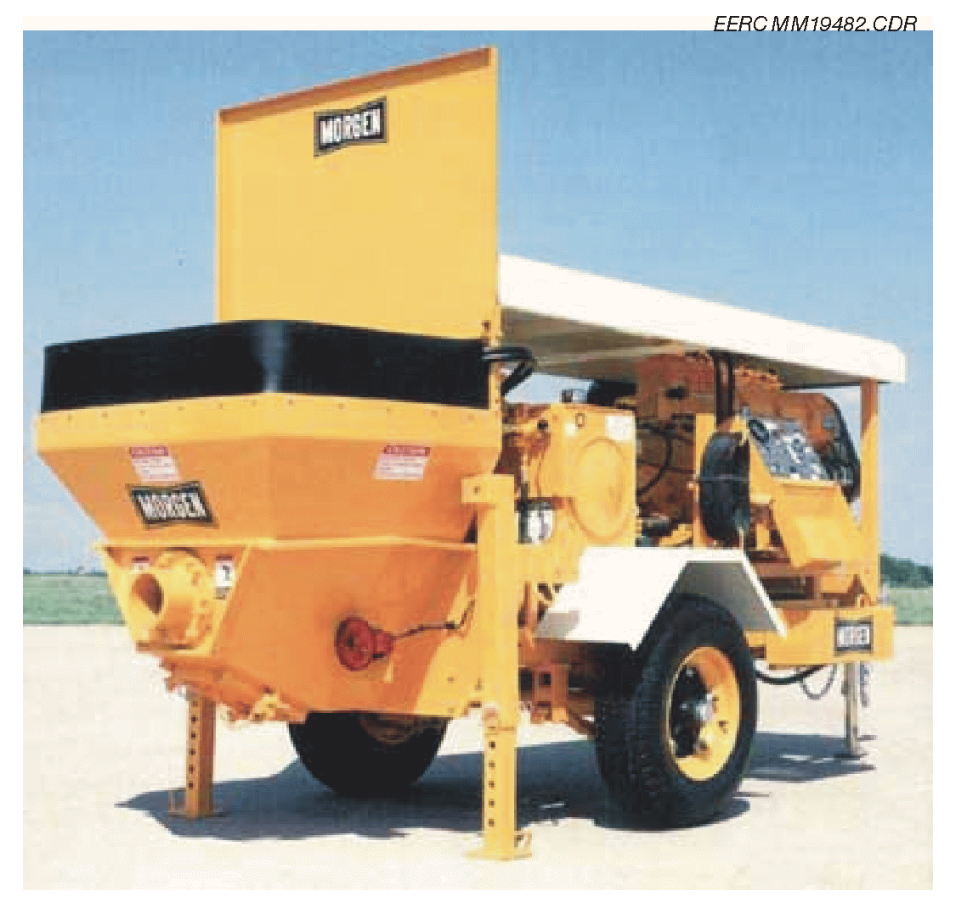

Figure 4. Morgen Mustang trailer-mounted concrete pump.

EERC MM19481.CDR

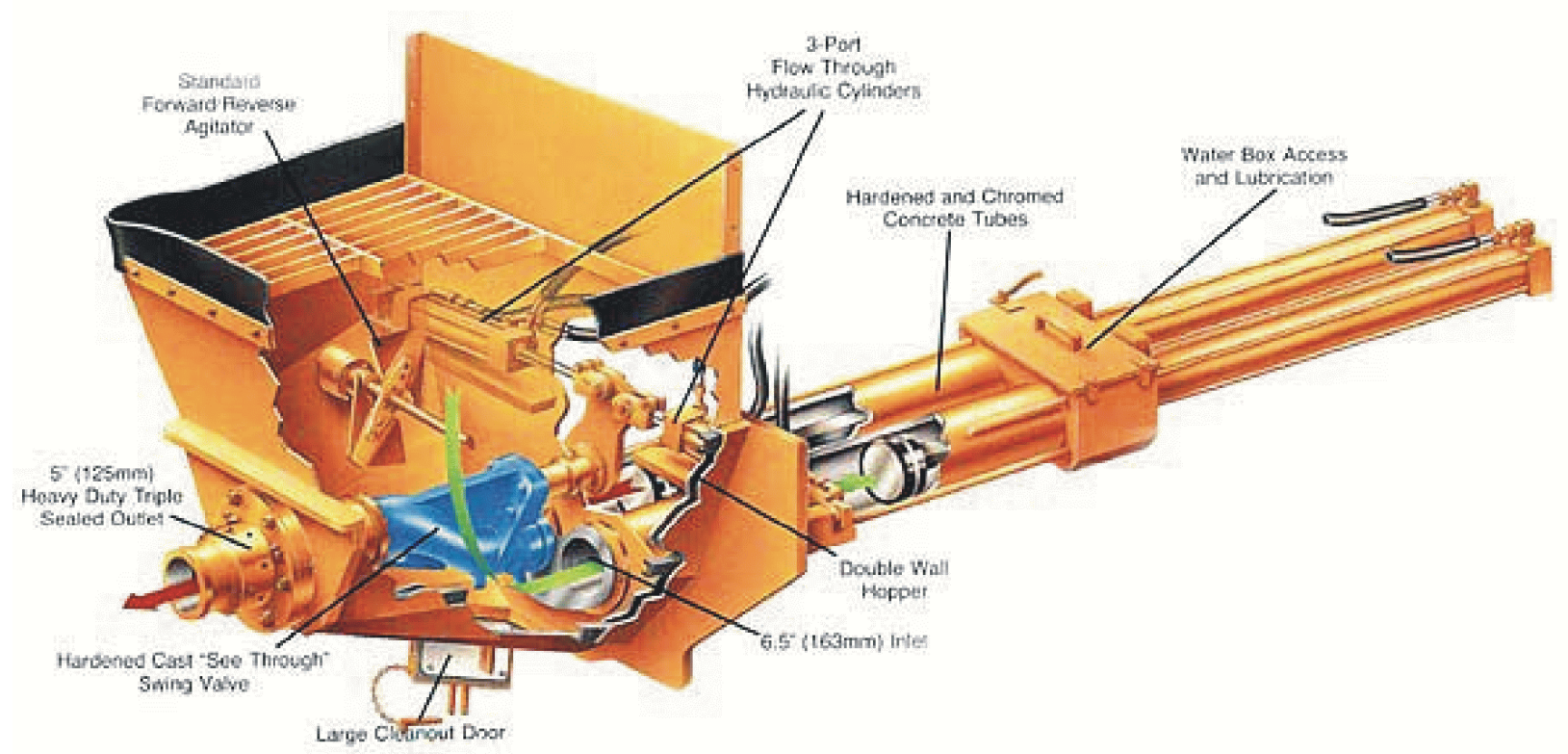

Figure 5. Cutaway diagram of Morgen Mustang concrete pump. 
pumping rate of $12 \mathrm{gpm}\left(100 \mathrm{ft}^{3} / \mathrm{hr}\right)$. The proposed system would consist of twin overlapping screw flights, both with inward rotation. The overlapping flights would function to provide self-cleaning and inhibit buildup of sticky sludge. Pressure containment would be attained by housing the twin screws in a pipe/flange system rated for a minimum pressure of $410 \mathrm{psig}$.

Bid specifications for constructing a pilot-scale twin-screw auger were forwarded to six conveyor manufacturers. Five of the six vendors declined to participate. The remaining vendor, Unico Services (47), claimed experience in producing screw augers used for the controlled removal of high-temperature ash from two demonstration-scale gasifiers. The system quoted by Unico was $\$ 45,000$, which was deemed excessive. Subsequent to the bid process, attention has focused on possibly building a system in-house with purchased components. Critical to the development of the pressurized-screw feeder is a shaft seal that can seal at 410 psig. Discussions with eight shaft seal vendors indicated that nothing is available off the shelf. The seal manufacturers would require significant engineering time to develop new or modify existing designs. Most vendors declined further involvement, knowing the request was for no more than two seals. One vendor offered a quote of $\$ 3000$ per seal. The EERC believes, based on its own experience, that in-house shaft seals can be manufactured more quickly and cheaply.

\section{Pneumatic Injection}

Pneumatic injection is presently the focus of sludge-feeding options. Design options have focused principally on the application of a shotcrete nozzle, a tool used for wet concrete "gunning." Shotcrete nozzles intimately mix compressed air with concrete in a converging pipe, resulting in a high-velocity stream (100 to $200 \mathrm{ft} / \mathrm{sec})$ of concrete that can be deposited on vertical services at distances of several feet to 20 feet or more from the nozzle. These nozzles can feed concrete with aggregate up to $3 / 4$ " in diameter. It is presumed that recycle syngas available at Wabash River can replace air as the pneumatic transport fluid. Preliminary estimations show that the sludge:syngas volume ratio available for the Wabash River gasifier is similar to the concrete:compressed air ratios normally achieved with the nozzle.

Several shotcrete nozzle manufacturers were identified. A $2 \frac{1}{2}$-inch nozzle with a rated capacity of approximately $24 \mathrm{yd}^{3} / \mathrm{hr}$ concrete was purchased from Shotcrete Technologies (48). A schematic of the nozzle is shown in Figure 6 and an actual picture of the nozzle is shown in Figure 7.

In addition to the shotcrete nozzle, a different nozzle design was proposed based on a lance used by the Western Lake Superior Sanitary District (Duluth, Minnesota) (49) for feeding 16 wt\% solids sludge to an atmospheric-pressure fluid-bed incinerator. A schematic of the sludge lance is shown in Figure 8. The lance shown uses a conical-shaped insert at the discharge of the 6-inch pipe lance to mechanically break up the sludge upon injection into the fluid bed. As the requirements for sludge dispersion would be much more severe for an entrained-flow system, proposed modifications included perforating the angled face of the insert to allow introduction of high-velocity jets of recycle syngas that would ideally disintegrate the sludge cake and carry the sludge into the gasifier. The confidence level in this design is less than that of the shotcrete nozzle. This design approach could be revisited based on results with the shotcrete nozzle. 


\section{SHOT-TECH NOZZLE ASSEMBLY}

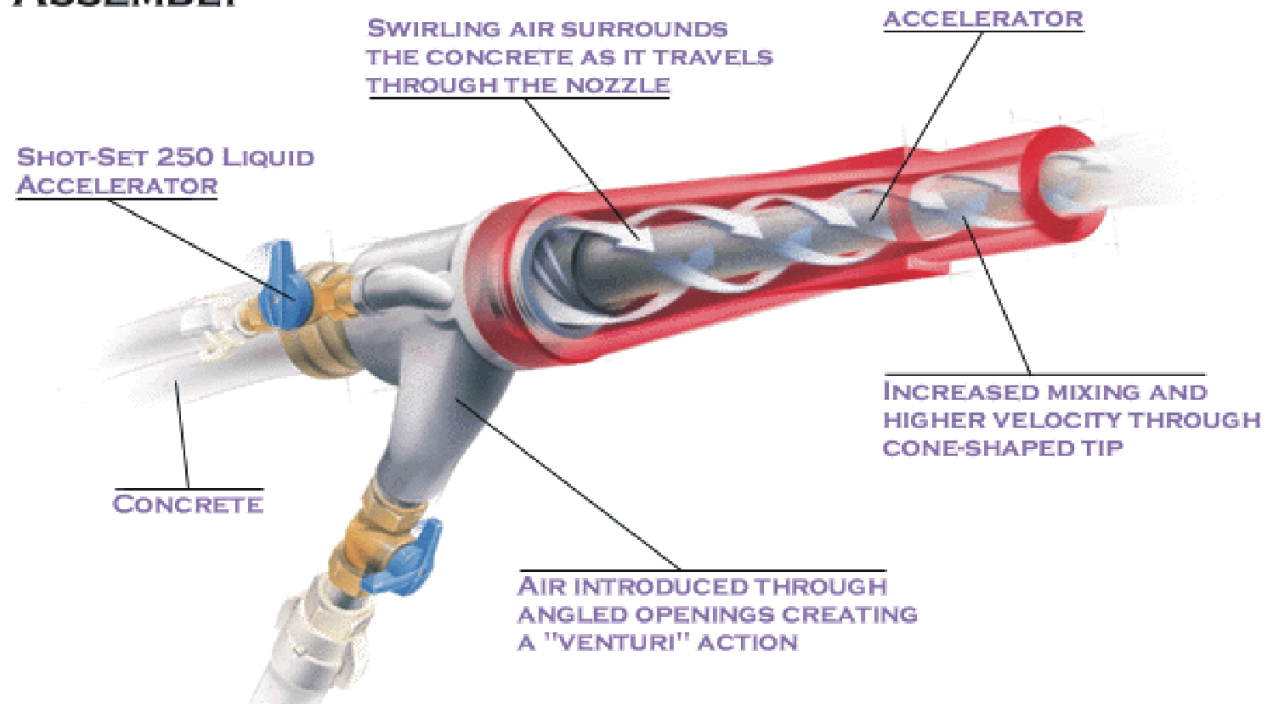

Figure 6. Cutaway diagram of Shotcrete Technologies shotcrete nozzle.

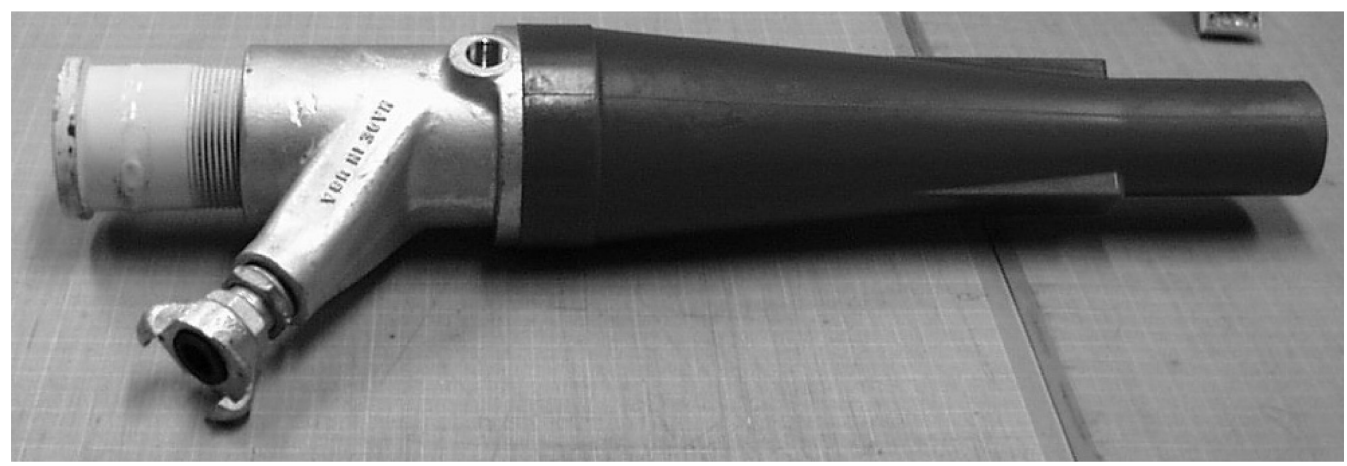

Figure 7. Shotcrete Technologies $2 \frac{1}{2} 2$-inch shotcrete nozzle. 


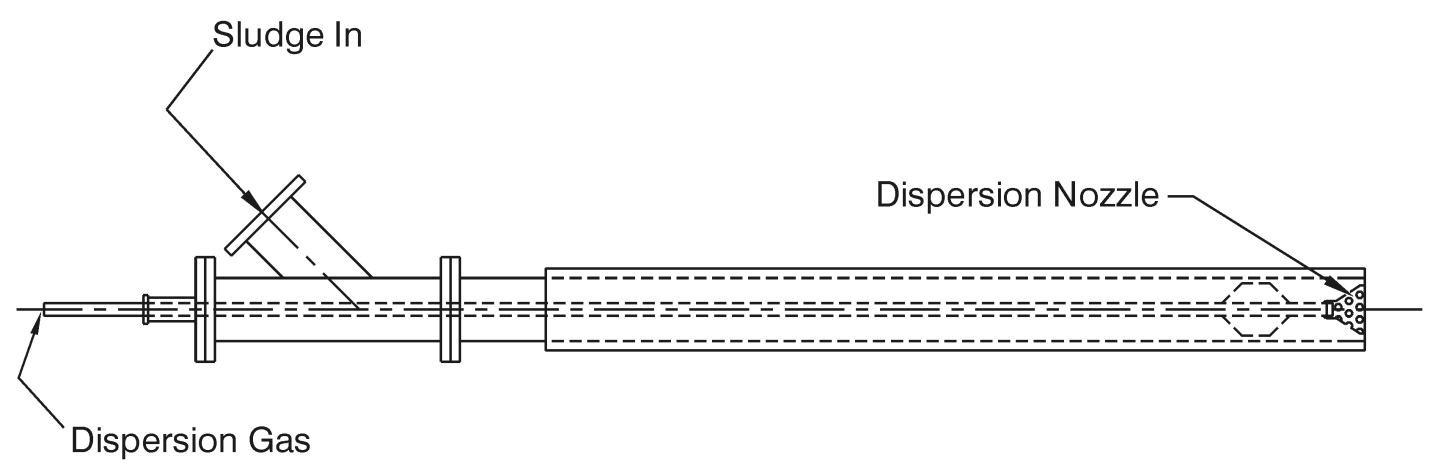

Figure 8. Sludge dispersion nozzle.

\section{EVALUATION OF FEED SYSTEM COMPONENTS}

Presently, the process envisioned for evaluating the proposed sewage sludge-feeding system includes the following:

1. The Morgen concrete pump will be evaluated first. Shakedown testing will determine if the $23 \mathrm{wt} \%$ solids Fargo sludge can be drawn into the piston chamber without assistance from a twin-screw feeder. It is possible that the sludge could be preheated (to perhaps $150^{\circ} \mathrm{F}$ ) to reduce viscosity and improve flowability. If the sludge cannot be adequately charged to the Morgen pump, testing will transition to lease and utilization of the Schwing pump.

2. The selected pump will then be used to verify sludge feeding in a 410-psig atmosphere. Shakedown testing will be performed using water. Testing with sludge will give an indication of the ability of the poppet valves on the Schwing valve or the floating ring seal on the Morgen pump to prevent material backflow when pumping into a pressurized atmosphere. The system designs for pump testing at 410 psig are discussed below.

3. The selected pump will then be used to evaluate the efficacy of the shotcrete nozzle for dispersing sewage sludge in a directed high-velocity stream. Nitrogen will be used to simulate the recycle syngas. The system designs for shotcrete nozzle testing are discussed below. 


\section{Pressure Vessel/Piping for Pump Testing}

Two separate systems have been designed for testing the ability of the piston pumps to deliver sludge into a 410-psig pressurized atmosphere. The first design was based on a dual-purpose pressure vessel, shown in Figure 9. This 4-ft-diameter, 8-ft-long vessel was intended firstly as a receiving vessel for sludge and, secondly, as a dry biomass feed vessel for potential demonstration with a transport reactor at the EERC. The lower section could be unbolted to remove the sludge between tests. The upper nozzle would be the point at which sludge would be introduced into the vessel. The nozzle was sized to also allow attachment of a pressurized twin-screw auger for sludge feeding. The lower nozzle would be the point at which dry biomass would be withdrawn if the vessel were used as a pressurized hopper/feeder. The vessel size was based on the volume requirement for 1-hour capacity of biomass with a bulk density of $10 \mathrm{lb} / \mathrm{ft}^{3}$.

Four fabrication shops with American Society for Testing and Materials certification for pressure vessel construction were contacted to provide a quote for cost and construction time. Three shops provided bids, and the fourth declined to participate. Bid prices ranged from $\$ 20,000$ to $\$ 41,000$, with vessel delivery periods ranging from 10 to 12 weeks. The cost and delivery periods seemed excessive for this project. Additionally, because of the vessel size and pressure requirements, the weight of the vessel was estimated by the shops at $6 \frac{1}{2}$ tons. This weight would present significant challenges with respect to movement and placement in the gasifier structure. Based on the unacceptable cost, delivery period, and weight, this pressure vessel concept was shelved.

A second option explored was the construction of a smaller vessel using 10-inch-diameter carbon steel pipe, shown in Figure 10. The vessel was sized for 10 minutes of sludge pumping at a

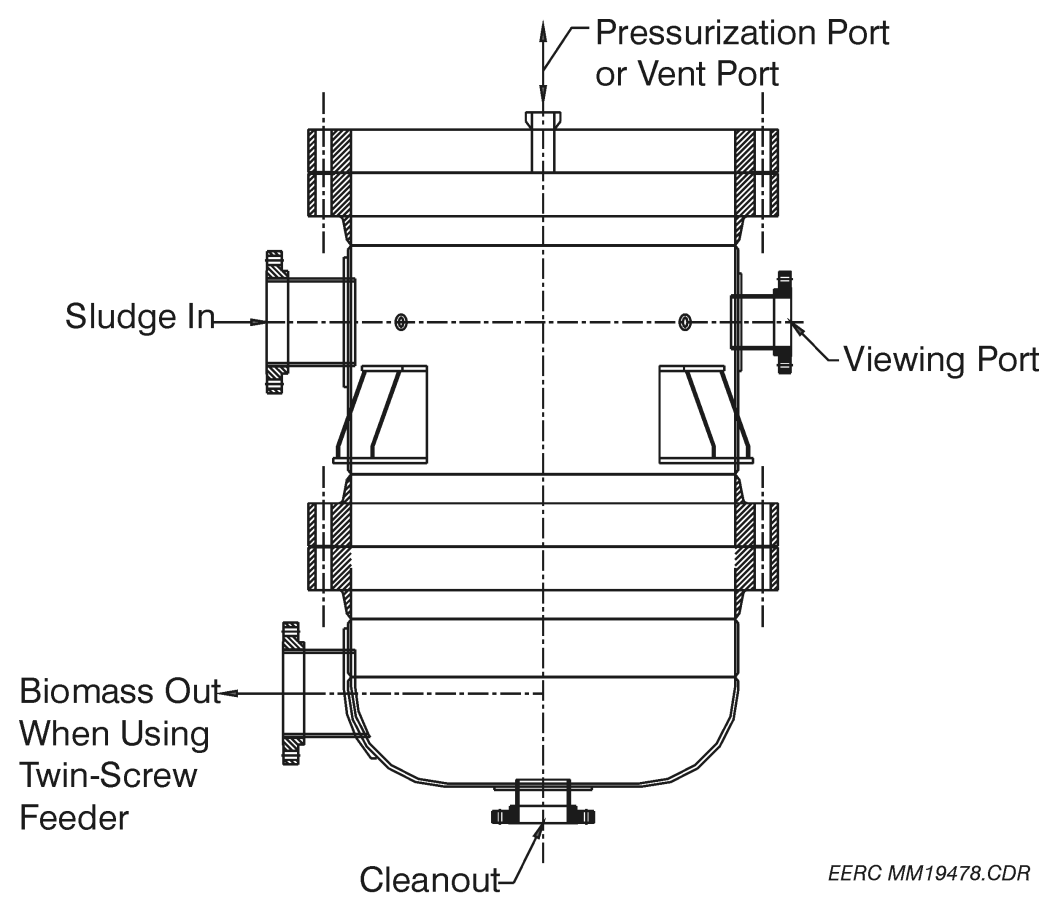

Figure 9. Large pressure vessel for elevated-pressure sludge system. 


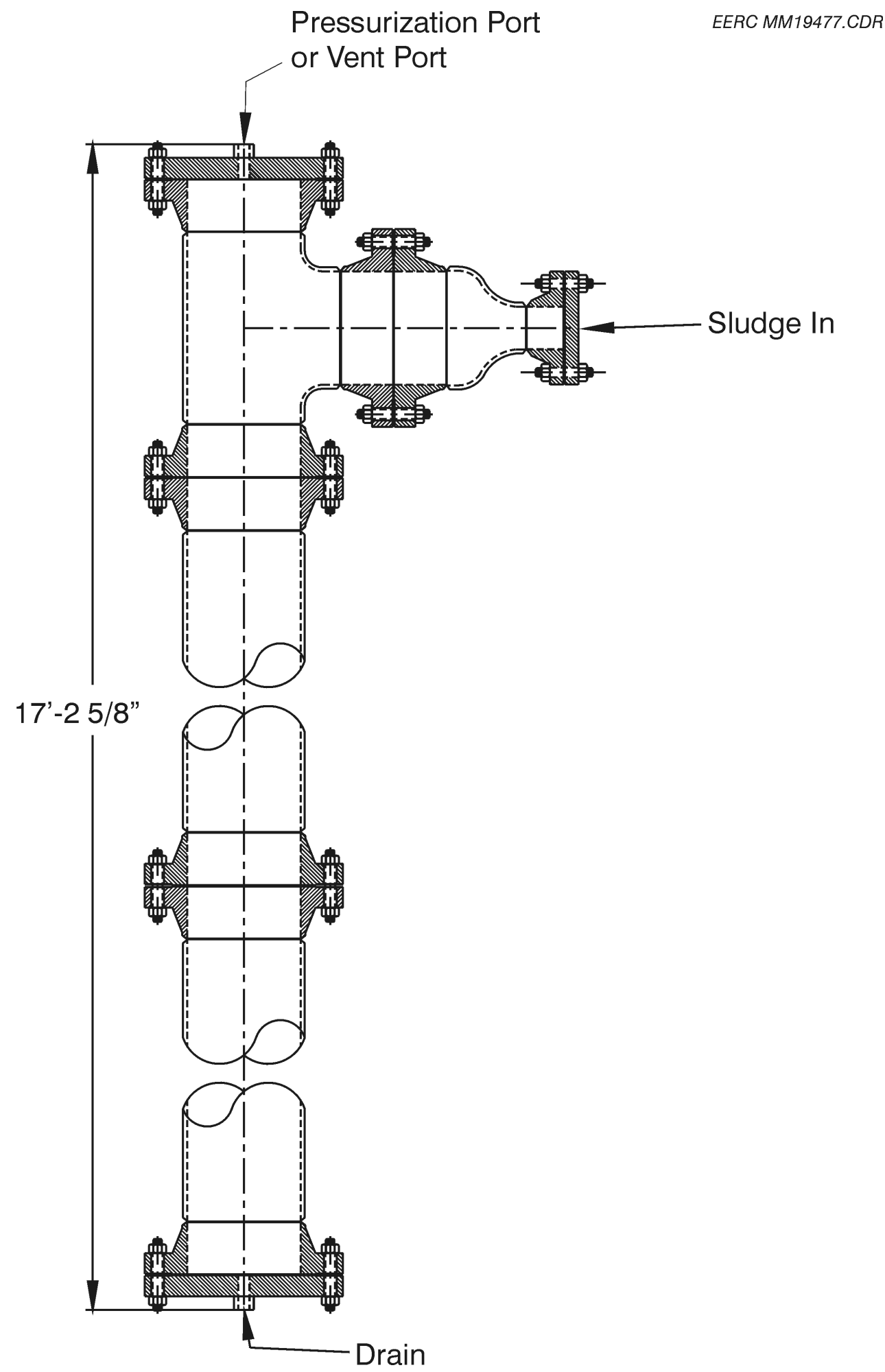

Figure 10. Pressure piping system for elevated-pressure sludge pump testing. 
nominal feed rate of $6 \mathrm{gpm}$. The vessel could potentially have secondary use as the pressure containment vessel for a twin-screw auger that could be demonstrated with other dry biomass materials. Vessel construction has been initiated.

To evaluate the pump, the pressure vessel would first be pressurized to 410 psig with nitrogen. The sludge pump would be isolated from the pressure vessel using an on-hand 4-inch full port ball valve rated for $720 \mathrm{psig}$. The sludge pump would begin pumping sludge up to the ball valve after which the valve would be opened to allow flow of sludge to the pressure vessel. A backpressure control valve would be used to vent nitrogen from the vessel and maintain the desired test pressure. The EERC is presently equipped with a house nitrogen supply of 700 psig.

\section{Evaluation of Sludge Dispersion}

Two separate systems have been designed for the evaluation of sludge dispersion. The first system, shown in Figure 11, was intended to allow injection of the dispersed sludge into an entrainment column. The entrainment column would be fed at the bottom with air from a blower. Although operated at atmospheric pressure and ambient temperature, the flowing conditions of the entrainment tower would produce particle drag and lift essentially equivalent to those achieved in the Wabash River gasifier. The entrainment tower would be ported to allow attachment of a pneumatic dispersion device such as the shotcrete nozzle (or other) or a twin-screw conveyor.

The second system was designed principally for evaluation of the shotcrete nozzle. This system consists of a 9-ft-long, 19-inch-diameter carbon steel pipe with several ports along its length. It is proposed that the sludge pump be positioned with the attached shotcrete nozzle at or near the

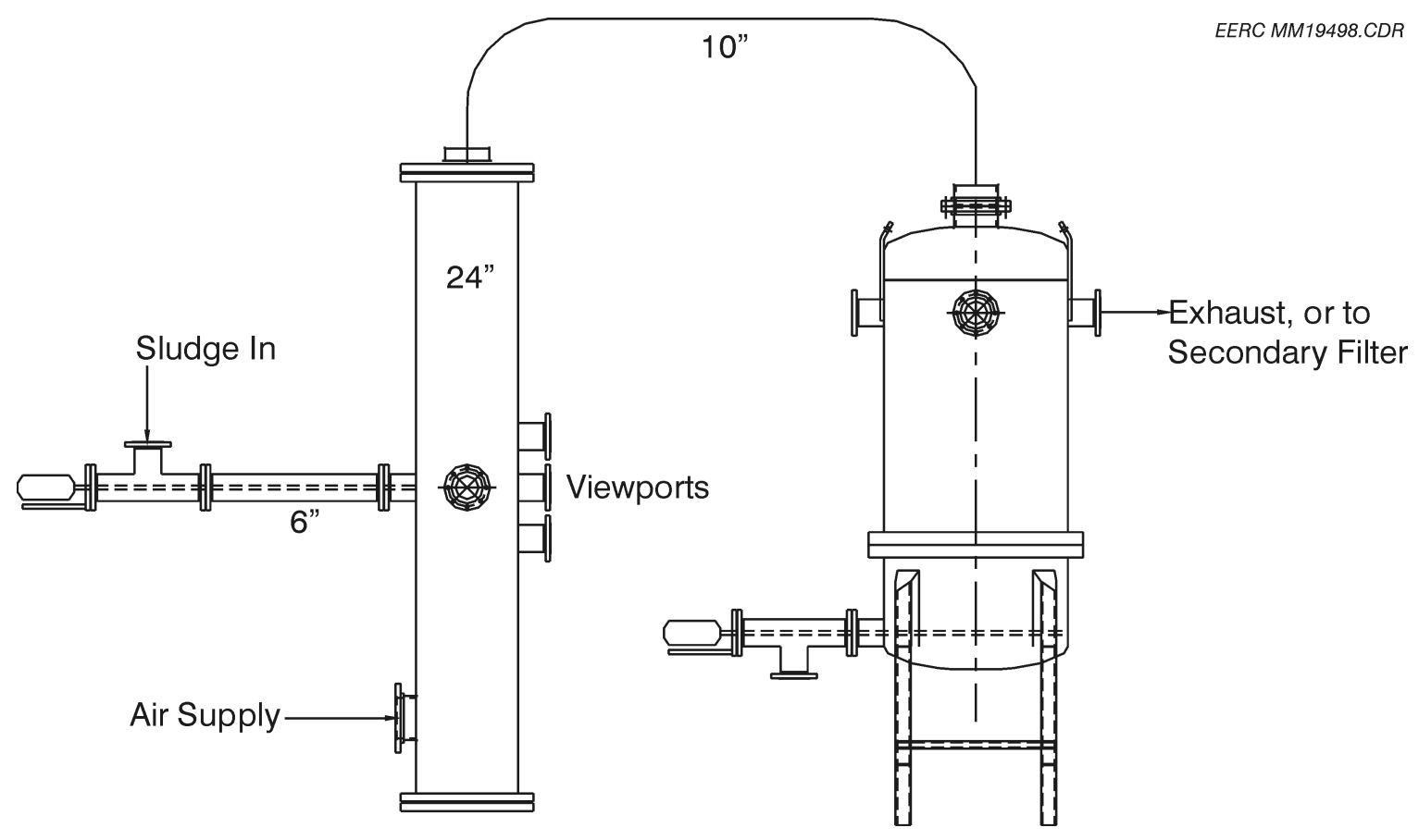

Figure 11. Sludge dispersion and entrainment column. 
entrance of the horizontally oriented pipe. Sludge impacting on the end panel will fall through the lower port. The side ports located within $2 \frac{1}{2} \mathrm{ft}$ and $5 \frac{1}{2} \mathrm{ft}$ of the entrance will be covered with plexiglass to allow observation of the nozzle spray. Strobe photography will be tested as a method of measuring the spray pattern and the associated sludge particle sizes. Nitrogen will be used as the pneumatic dispersion medium in the nozzle (or subsequent nozzle designs). The existing nitrogen supply system for the EERC transport reactor will be used to control/measure the volume rate of nitrogen to the nozzle. This will allow determination of the sludge:nitrogen volume ratio required for dispersion.

\section{PATENT DATABASE SEARCH FOR HIGH-PRESSURE SOLIDS FEED SYSTEMS}

A Web-accessible database of U.S. and foreign patents (Delphion Intellectual Property Network, http:/www.delphion.com/home) was searched to determine the status of dry feed systems for high-pressure applications (50). Queries were limited to U.S. patents only. A list of related patents is presented in Appendix B.

Review of the patents indicated that the systems were principally based on extrusion feeding of powdered or pulverized coal. A gas-tight pressure seal was apparently demonstrated to be achieved by one of two means; 1) attaining the plastic deformation state of the coal, resulting in void sealing, or 2) adding an uncompressible filler/binder such as water or a hydrocarbon liquid to fill voids. The forces of extrusion, however, resulted in sufficient compaction of the coal to require the feed system to also incorporate a means of repulverizing or delumping the compact. This was typically achieved using a directed stream of high-pressure fluid (gas or liquid).

\section{PROCUREMENT OF SAMPLES AND SAMPLE ANALYSIS}

A number of potential feedstocks for evaluation within this program have been procured. They include corn stover, soybean hulls, RDF, and municipal sewage sludge. Corn stover was procured from Tom Schechinger of Iron Horse Custom Farming (Harlan, Iowa). Corn stover has principally been evaluated for production of high-value products such as furfural, fibers, and ethanol. Soybean hulls were obtained from Darcy Ehmann of Ag Processing Inc. (Omaha, Nebraska). Soybean hulls are typically shredded and extruded into pellets as cattle feed. The unpelleted soybean hulls would appear to be an ideal fuel for entrained flow gasification in that they are of sufficiently small size and low density to preclude any requirement for size reduction.

RDF was procured from the Ramsey/Washington County Resource Recovery Facility (Newport, Minnesota), owned and operated by N-R-G Energy, Inc. (51). The facility can process 1500 tons/day of MSW, which comprises $60 \%$ commercial waste and $40 \%$ residential waste. The facility achieves $84 \%$ to $90 \%$ recovery as RDF. Approximately $5 \%$ of the MSW is recovered as ferrous using magnetic separation and $1 \%$ is recovered as aluminum using eddy current separation. The RDF is consumed in two separate power generation facilities owned and operated by Xcel Energy (formerly Northern States Power Company). 
The Newport RDF facility was toured to observe the scale and complexity of the operation and to retrieve a sample of RDF. An approximately 3-lb sample, filling a volume equivalent to three 5gallon pails, was obtained. The material was hand-sorted and classified into the following categories: cardboard, paper, plastic, textiles, wood, aluminum, ferrous, food waste, and glass/ ceramic. A fluff fraction was also generated that consisted of material that, because of its small size, would have been time-consuming to sort. The results of the sorting are presented in Table 11; pictures of the sorted fractions are shown in Appendix C.

\section{TABLE 11}

RDF Sorting Results

\begin{tabular}{|c|c|c|c|}
\hline Material & $\begin{array}{l}\text { Mass, } \\
\text { grams }\end{array}$ & $\begin{array}{l}\text { Weight } \\
\text { Percent }\end{array}$ & Comment \\
\hline Cardboard & 238 & 11.3 & \\
\hline Paper & 632 & 30.1 & \\
\hline Plastic & 248 & 11.8 & $\begin{array}{l}\text { Mostly film plastic (from grocery bags or similar to envelope windows); } \\
\text { Styrofoam; pop jugs; little dense plastic }\end{array}$ \\
\hline Textiles & 146 & 7.0 & Foam padding, carpet fibers, fiber fill for jackets, some rubber \\
\hline Fluff & 288 & 13.7 & Material too small to sort by hand; estimate $90 \%$ paper \\
\hline Wood & 44 & 2.1 & \\
\hline Aluminum & 16 & 0.8 & 6 grams of aluminum foil, 10 grams of aluminum castings or stamped product \\
\hline Ferrous & 3 & 0.1 & Single piece of wire \\
\hline Food Waste & 4 & 0.2 & Orange peel, dried bread chunks \\
\hline Glass, Ceramic & 8 & 0.4 & \\
\hline$-4 \times 10$-mesh & 157 & 7.5 & $\begin{array}{l}\text { Styrofoam beads, wood splinters, colored foil, glass/plastic fragments, paper } \\
\text { fiber fluff }\end{array}$ \\
\hline$-10 \times 20$-mesh & 136 & 6.5 & Wood splinters, colored foil, glass/plastic fragments, paper fiber fluff, dirt? \\
\hline-20 -mesh & 180 & 8.6 & Paper fibers, dirt?, wood splinters, colored foil, glass/plastic fragments \\
\hline Total & 2100 & & \\
\hline
\end{tabular}

Analysis of the -4-mesh fraction indicated that it comprised $60 \%$ ash, principally due to the presence of glass fragments. These glass fragments, produced during hammermill crushing, were not removed during disk screening but were apparently adhered to the slightly damp paper and cardboard of the MSW. The MSW-to-RDF process appeared to do a good job of removing any dense, hard objects that could present problems in size reduction and feeding equipment.

As previously discussed, a 1-gallon sewage sludge sample was procured from the wastewater treatment facility in Indianapolis, Indiana. It was considered unlikely that this would be suitable material to procure in large quantities to accomplish feed system analysis testing at the EERC. Because the sludge is undigested, the short shelflife would necessitate immediate use. Further, the higher pathogen content would put operating personnel at higher risk of contamination. Consequently, a surrogate source of municipal sewage sludge was identified in Fargo, North Dakota, only 70 miles south of Grand Forks. This digested sewage sludge is similar in solids content and physical appearance and consistency. 
Repeated attempts to procure switchgrass from the Chariton Valley Biomass Project in Corydon, Iowa, have not been successful.

Select samples of biomass have been subjected to the following analysis: proximate, ultimate, heating value, XRF, and total chloride. Results of the analysis for soybean hulls, RDF, and sewage sludge from Indianapolis, Indiana, and Fargo, North Dakota, are presented in Table 12. The heating value for soybean hulls, RDF, and Indianapolis sludge were similar at about 7600 to $7800 \mathrm{Btu} / \mathrm{lb}$ (moisture-free, MF). The heating value of the Fargo sludge was lower relative to the Indianapolis sludge because of the combustible loss (as methane) during anaerobic digestion. The soybean hulls were superior to the other fuel types in terms of ash, sulfur, and total chloride contents. Potential issues of concern for these fuels potentially include the high total chloride content $(4630 \mathrm{mg} / \mathrm{g})$ for RDF and the high potassium content (44\% as oxide in ash) for soybean hulls.

The soybean hulls and RDF, along with cedar sawdust and molder shavings, were evaluated for bulk density. The purpose for determining bulk density for these materials was to assist in the sizing of equipment for potential feed system designs. Prior to density determination, the RDF was size-reduced in a knife shredder; separate fractions were produced using 1/16-inch and 1/4-inch round-opening screens. The cedar wood waste fractions were obtained from a local wood furniture manufacturer; these materials were not altered prior to bulk density determination. In addition to raw soybean hulls, soybean hulls sized to -1/8-inch (by AGP) were also tested.

Table 13 presents the bulk density results for the fuels. Because these biomass fuels are compactable, even under their own weight, a compacted density was determined by placing a weight on top of the fuel. The resulting compressed height was measured and a new bulk density calculated. The information is useful for estimating the mass of biomass that can be stored in a vessel of known height. The equivalent height of biomass that produces the higher bulk density is shown in the far right column.

The results show that for the same weight of compaction, some biomass materials were considerably more compressible than others. The RDF, which at the tested sizes largely resembles fluffed paper fibers, exhibited an approximate doubling of bulk density for both sizes tested. The shredded soybean hulls appear to be relatively uncompactable.

\section{COMMERCIAL DRY BIOMASS FEED SYSTEMS}

Two commercial feed systems have been identified to date that were deemed to have potential for biomass feeding to the Wabash River or equivalent gasifier: the Posimetric Feeder by Pennsylvania Crusher (52) and the Macawber Engineering "Controlveyor" pneumatic injection system (53). Vendors for both systems were contacted for information on 1) known applications at 410 psig or higher and 2) availability of a system for testing at the EERC.

The Posimetric feeder was developed by Stamet with financial assistance from the DOE Small Business Innovation Research program. Its principal application has been for the nonpulsating metered feeding of lump coal to crushers in coal-fired power plants. The feeder uses a spool-shaped 


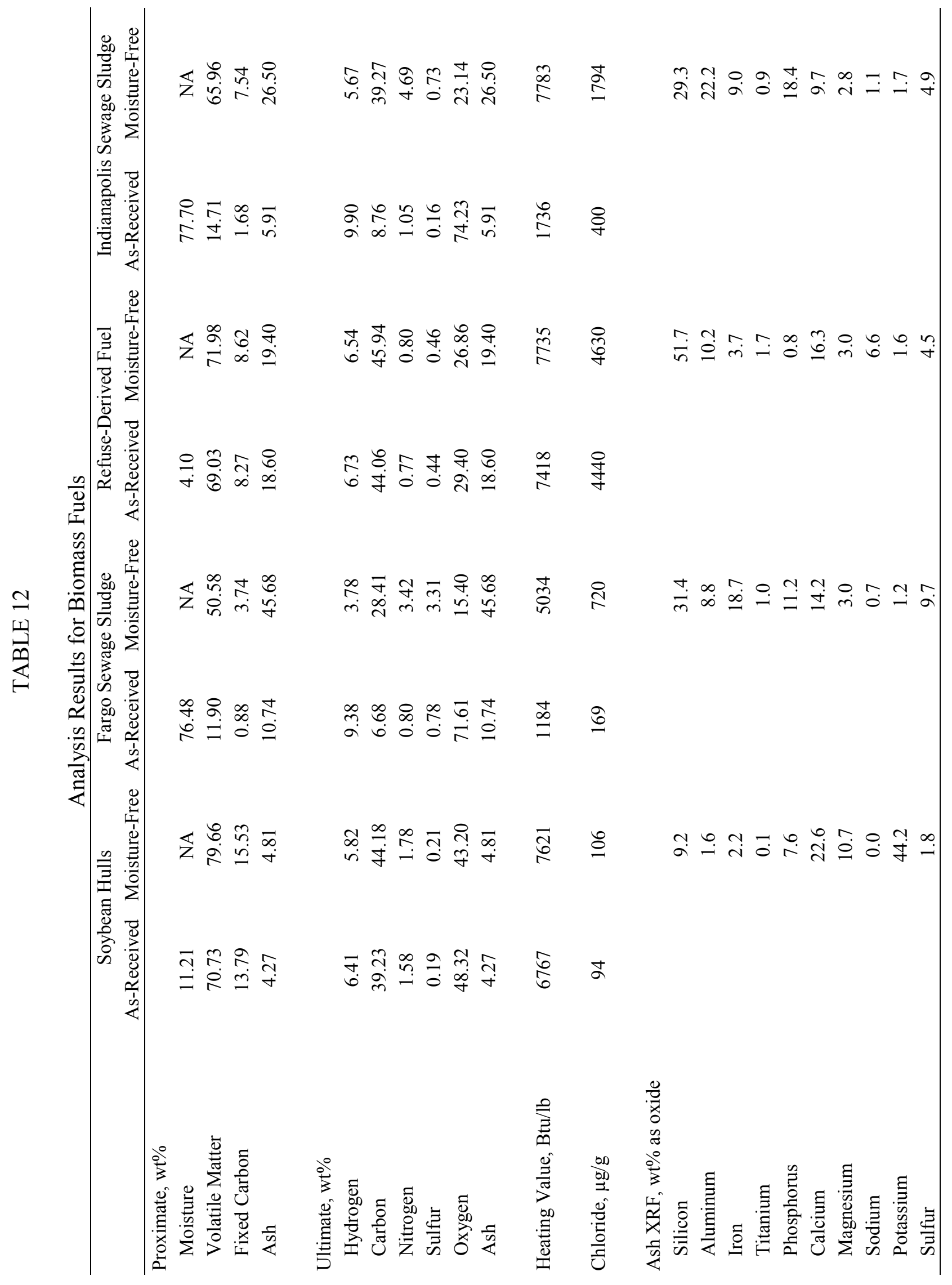




\section{TABLE 13}

Bulk Densities Measured for Select Biomass Materials

\begin{tabular}{lccc}
\hline Biomass & $\begin{array}{c}\text { Uncompacted Bulk } \\
\text { Density, } \\
\mathrm{lb} / \mathrm{ft}^{3}\end{array}$ & $\begin{array}{c}\text { Compacted Bulk } \\
\text { Density, } \\
\mathrm{lb} / \mathrm{ft}^{3}\end{array}$ & $\begin{array}{c}\text { Equivalent Height for } \\
\text { Compacted Density, } \\
\mathrm{ft}\end{array}$ \\
\hline Raw Soybean Hulls & 7.4 & 8.7 & 7.0 \\
- 1/8" Soybean Hulls & 20.7 & 22.2 & 2.5 \\
Cedar Sawdust & 6.8 & 9.1 & 7.6 \\
Cedar Molder Shavings & 3.5 & 6.0 & 14.7 \\
-1/16" RDF & 8.8 & 14.9 & 5.9 \\
$-1 / 4$ " RDF & 4.3 & 9.1 & 12.1 \\
\hline
\end{tabular}

disk to move wet or dry solids through a partial rotation to the discharge. The feeder relies on "bridging" of the fuel with the spool to achieve feeding. Further, "packing" of the fuel supposedly will result in eliminated or greatly reduced backflow of process gas or liquid. Marketing literature by Stamet indicate that the Posimetric feeder has been demonstrated to deliver coal into a 210-psig atmosphere (54). However, discussions with the vendor indicate that more recent tests show difficulties at maintaining a gas seal in tests at $250 \mathrm{psig}$. Further, no systems were in place or being developed for application at pressures approaching 410 psig.

The Macawber Engineering Controlveyor system uses pneumatic injection to achieve continuous feeding of fine powders, granular, or lump materials. The system has been used in the metal industry for applications such as fuel feeding to cupolas and blast furnaces. Company literature indicates experience with systems at elevated pressures, even up to 450 psig. Feed rate capacities range from less than a pound per minute to more than 1 ton per minute. Discussions with the vendor indicated that Macawber has limited experience with biomass injection systems and limited experience with injection of coal into a pressurized gasifier but no experience with pressurized injection of biomass into a gasifier. The vendor was to check with a sister company in Europe (Mactenn Systems) with whom the biomass experience resides. Presently, Macawber has no systems in development for pressures over $150 \mathrm{psig}$. Macawber does not have Controlveyor systems for offsite evaluation. Testing capabilities at Macawber do not include actual demonstration with a Controlveyor system but rather consist of evaluation of parameters for pneumatic conveying of the selected materials.

\section{CONCLUSIONS AND FUTURE PLANS}

Preliminary conclusions for the ongoing project are as follows:

- Several potential alternative fuels have been obtained for evaluation and testing as potential feedstocks, including sewage sludge, used railroad ties, UWW, MSW, and used waste tires/tire-derived fuel. Only fuels with potential tipping fees were considered; potential energy crop fuels were not considered since they would have a net positive cost to the plant. 
- Based on the feedstock assessment, sewage sludge has been selected as one of the primary feedstocks for consideration at the Wabash plant.

- Because of the limited waste heat available for drying and the ability for the gasifier to operate with alternative feedstocks at up to $80 \%$ moisture, a decision was made to investigate a pumping system for delivering the as-received fuel across the pressure boundary.

- High-temperature drop-tube furnace tests were conducted to determine if explosive fragmentation of high-moisture sludge droplets could be expected, but showed that these droplets underwent a shrinking and densification process that implies that the sludge will have to be well dispersed when injected into the gasifier.

- Fuel dispersion nozzles have been obtained for measuring how well the sludge can be dispersed in the second stage of the gasifier.

Future work includes leasing a Schwing Amercia pump to test pumping sewage sludge against 400 psig. In addition, sludge dispersion testing will be completed using the two different dispersion

nozzles to determine their ability to generate sludge particles small enough to be entrained out of the E-Gas entrained-flow gasifier.

\section{REFERENCES}

1. Smith, D. White River Environmental Partnership, Indianapolis, IN. Wastewater treatment plant information, 2001.

2. Cussen, K. White River Environmental Partnership, Indianapolis, IN. Wastewater treatment plant information, 2001.

3. Holmes, C. White River Environmental Partnership, Indianapolis, IN. Wastewater treatment plant information, 2001.

4. Merrell, T. Merrell Brothers Inc. Sludge transport cost estimates, 2001.

5. Klatt, T. Today Cartage. Sludge transport cost estimates, 2001.

6. Metropolitan Water Reclamation District of Greater Chicago. http://www.mwrdgc.dst.il.us/role.htm (accessed October 2001).

7. Cook, E.J. Deputy Chief Engineer, Metropolitan Water Reclamation District of Greater Chicago, Chicago, IL. Wastewater treatment information, 2001.

8. Bergman, B. Metropolitan Water Reclamation District of Greater Chicago, Chicago, IL. Stickney site sludge production and treatment information, 2001. 
9. Sundera, J. Metropolitan Water Reclamation District of Greater Chicago, Chicago, IL. Calumet site sludge production and treatment information, 2001.

10. Metcalf \& Eddy, Inc. Wastewater Engineering, Treatment, Disposal, and Reuse, 3rd ed.; McGraw-Hill, Inc.: New York, 1991; 883 p.

11. Rebacz, S. Rebacz Trucking, IN. Sludge transport cost estimate, 2001.

12. Hornical, G. Water Production Division, City of Decatur, IL. Municipal sewage sludge information, 2001.

13. Andrews, A. City of Lafayette, IN. Municipal sewage sludge information, 2001.

14. Limon, R. City of Urbana-Champaign, IL. Municipal sewage sludge information, 2001.

15. Dompke, S. City Utilities, Bloomington, IN. Municipal sewage sludge information, 2001.

16. Schmidt, D.D.; Pinapati, V.S. Opportunities for Small Biomass Power Systems; Final Technical Report for U.S. Department of Energy Contract No. DE-FG02-99EE35128; Energy \& Environmental Research Center: Grand Forks, ND, Nov 2000.

17. U.S. Department of Commerce U.S. Census Bureau. http://www.census.gov/population/estimates/metro-city/ma99-01.txt (accessed Nov 2000).

18. Railway Tie Association. http://rta.org/pdf/tieanalysis.pdf (accessed Oct 2000).

19. Railway Tie Association. http://rta.org/two_tier/industry_stats_1.htm (accessed Oct 2000).

20. Association of American Railroads. http://www.aar.org/aarhome.nsf?OpenDatabase (accessed Nov 2000).

21. Hellsly, D. Norfolk Southern Railroad. Railroad tie replacement information, 2001.

22. Wiens, M. Burlington Northern Santa Fe Railroad. Railroad tie replacement information, 2001.

23. Rawson, K. Union Pacific Railroad. Railroad tie replacement information, 2001.

24. Smith, G. RailWorks Wood Waste Energy. Used railroad tie markets and cost information, 2001.

25. Johnson, D. Tampa International. Used railroad tie markets and cost information, 2001.

26. Welborn, J. CMS Generation, New Bern, NC. Used railroad tie fuel information, 2001. 
27. U.S. Department of Energy National Renewable Energy Laboratory. http://www.nrel.gov/biomass/doe/rbep/in_wdwaste (accessed Oct 2000).

28. Wiltsee, G. Urban Wood Waste Resource Assessment; Report for U.S. Department of Energy National Renewable Energy Laboratory; Appel Consultants, Inc., Nov 1998.

29. Access Indiana, State of Indiana. http://www.state.in.us/idem/olq/publications/far99 (accessed Oct 2000).

30. Illinois Environmental Protection Agency. http://www.epa.state.il.us/land/landfillcapacity/1998/index.html (accessed Oct 2000).

31. Illinois Environmental Protection Agency. http://www.epa.state.il.us/land/landfillcapacity/1999/index.html (accessed June 2001).

32. U.S. Environmental Protection Agency

33. Biocycle

34. Access Indiana, State of Indiana. http://www.state.in.us/idem/soe/99report/land/land.pdf (accessed Oct 2000).

35. Jensen, J. Auburndale Recycling Center, Inc., Auburndale, WI. Tire-derived fuel information, 2001.

36. Auburndale Recycling Center, Inc. http://www.auburndalerecycling.com/companyprofil.htm (accessed Oct 2000).

37. PRIMEDIA Business Magazines and Media. http://industryclick.com/magazinearticle. asp? releaseid=6094\&magazinearticleid=96079\&s iteid=27\&magazineid=121 (accessed Oct 2000).

38. Astafan, C. Improving Scrap Tire Processing. Solid Waste Technologies 1997, Jan/Feb, $13-18$.

39. Kunii, D.; Levenspiel, O. Fluidization Engineering, 2nd ed.; Butterworth-Heinemann: Boston, MA, 1991; pp 62, 80-81.

40. McCabe, W.L.; Smith, J.C. Unit Operations of Chemical Engineering, 3rd ed.; McGrawHill: New York, 1976; pp 995-996.

41. Handbook of Tables for Applied Engineering Science, 2nd ed.; CRC Press, 1973; pp 177-178. 
42. SCHWING America Incorporated. http://schwing.com/products/c_pumps/index.html (accessed Sep 2000).

43. Putzmeister America. http://www.putzmeister.com (accessed Sep 2000).

44. Moyno, Inc. http://www.moyno.com/moyno/main.html (accessed Sep 2000).

45. Discflo Corporation. http://www.discflo.com (accessed Oct 2000).

46. Morgen Manufacturing Company. http://www.morgenmanufacturing.com/index.html (accessed Sep 2001).

47. Unico Services, Inc. http://www.unicoservices.com (accessed May 2001).

48. Shotcrete Technologies, Inc. http://www.shotcretetechnologies.com (accessed July 2001).

49. Western Lake Superior Sanitary District. http://www.wlssd.duluth.mn.us (accessed April 2001).

50. Delphion Intellectual Property Network. http://www.delphion.com (accessed Oct 2000).

51. N-R-G Energy, Inc. Ramsey/Washington County Resource Recovery Facility information, 2001.

52. Pennsylvania Crusher Corporation. http://www.penncrusher.com (accessed Nov 2000).

53. Macawber Engineering, Incorporated. http://www.macawber.com (accessed Jan 2001).

54. Hazardous Materials Management. http://www.hazmatmag.com/library/docs/ON95/ON95025.html (accessed Oct 2000). 
APPENDIX A

\section{PARAMETERS FOR TERMINAL VELOCITY EQUATIONS}




\section{PARAMETERS FOR TERMINAL VELOCITY EQUATIONS}

$d_{p}^{*} \quad$ Dimensionless particle size

$\mathrm{d}_{\mathrm{p}} \quad$ Particle size, $\mathrm{ft}$

$\rho_{\mathrm{g}} \quad$ Gas density, $\mathrm{lb} / \mathrm{ft}^{3}$

$\rho_{\mathrm{s}} \quad$ Particle density, $\mathrm{lb} / \mathrm{ft}^{3}$

g Gravitational constant, $32.2 \mathrm{ft} / \mathrm{sec}^{2}$

$\mu \quad$ Gas viscosity, $\mathrm{lb} / \mathrm{ft}-\mathrm{sec}$

$\mathrm{u}_{\mathrm{t}}{ }^{*} \quad$ Dimensionless terminal velocity, $\mathrm{ft} / \mathrm{sec}$

$\Phi \quad$ Sphericity, dimensionless

$\mathrm{u}_{\mathrm{t}} \quad$ Terminal velocity, $\mathrm{ft} / \mathrm{sec}$ 
APPENDIX B

\section{PATENTED HIGH-PRESSURE COAL FEED SYSTEMS}




\section{PATENTED HIGH-PRESSURE COAL FEED SYSTEMS}

US04206713 Continuous Coal-Processing Method

US04218222 Method of Charging Solids into Coal Gasification Reactor

US04302353 Method for the Production of Synthesis Gas

US04209304 Coal Gasification Method of Feeding Dry Coal

US04978369 Process for Feeding Carbonaceous Material into Reaction Spaces

US04255161 Apparatus for Introducing Solid Fuels into a Pressure Gasification Reactor

US03976548 Apparatus for Processing Coal and Like Material 
APPENDIX C

\section{RDF FRACTION PHOTOGRAPHS}




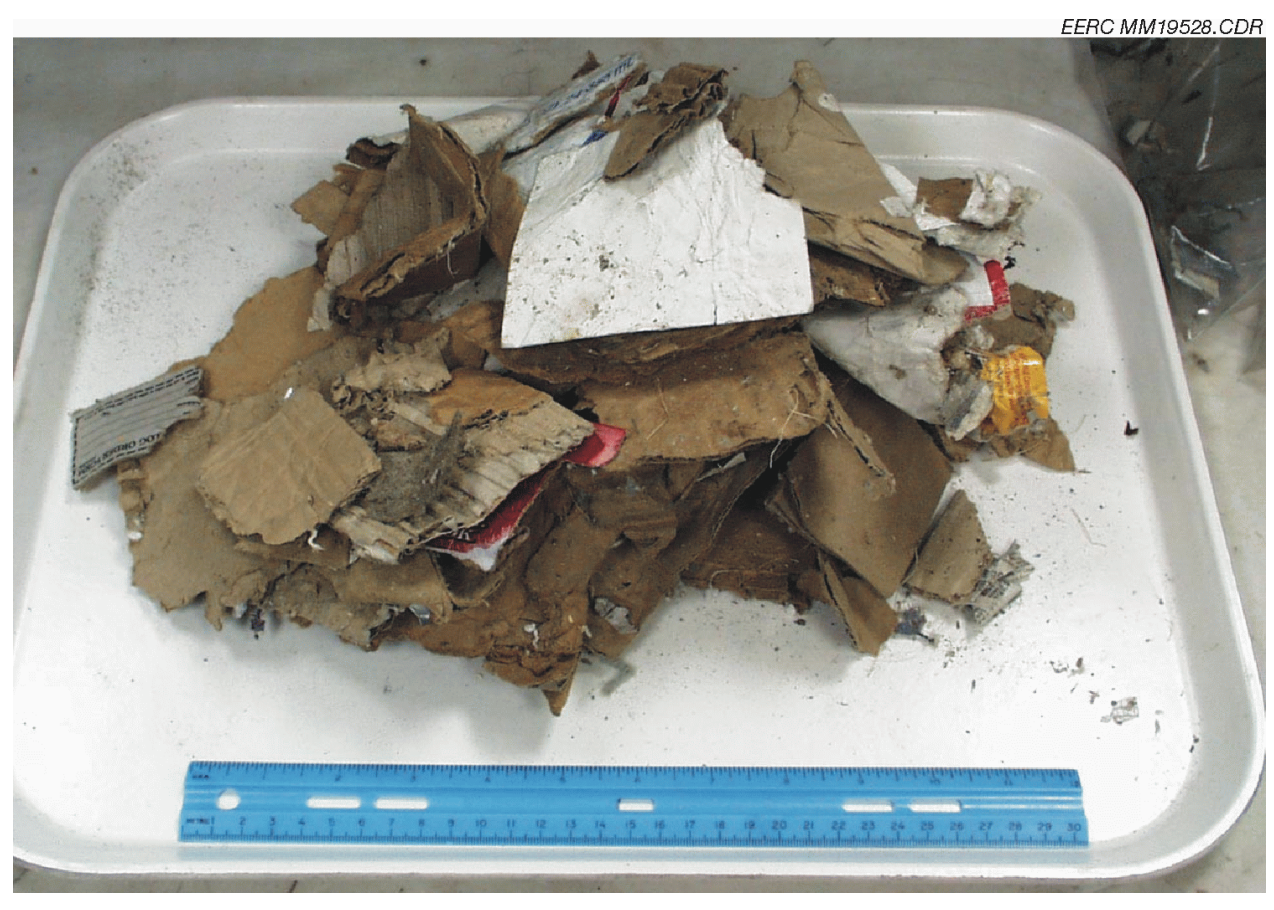

Figure C1. Cardboard fractions in RDF.

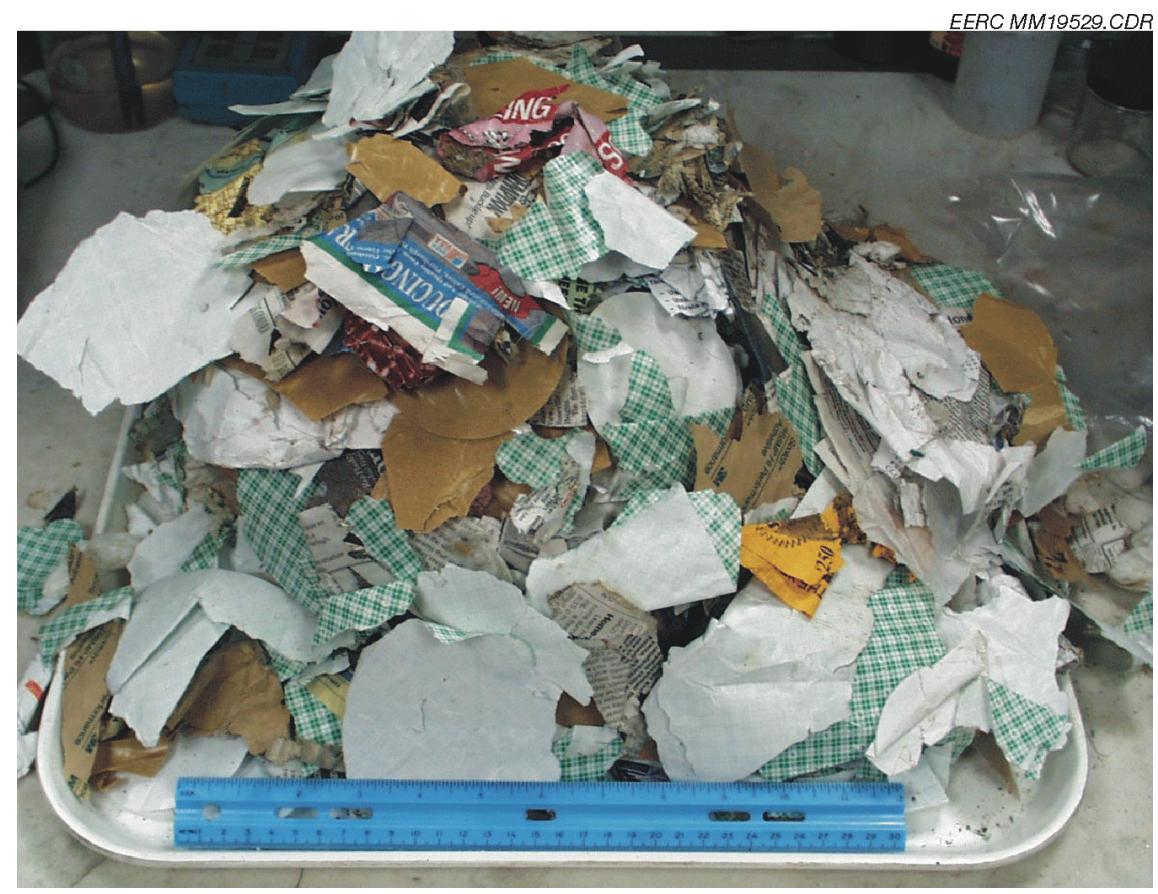

Figure C2. Paper fraction in RDF. 


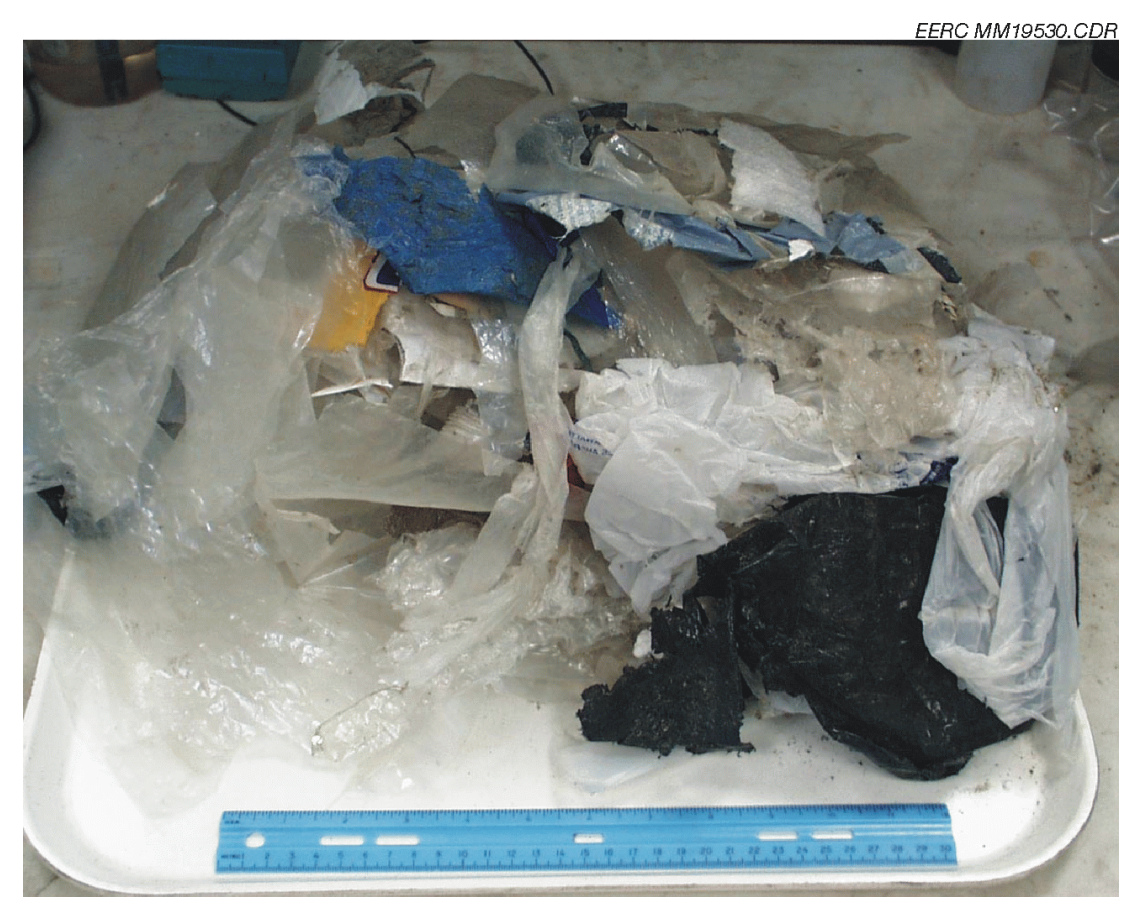

Figure C3. Plastic fraction in RDF.

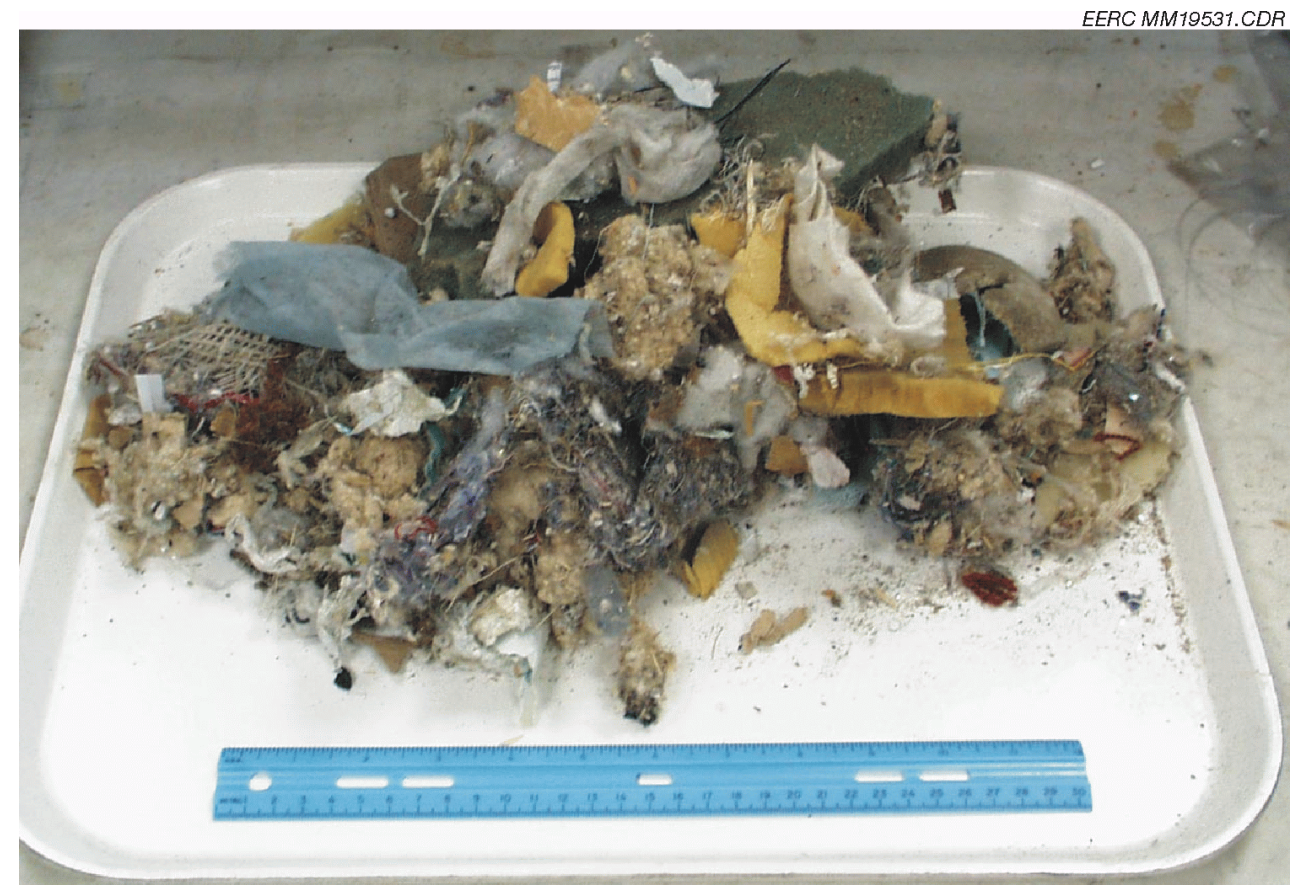

Figure C4. Textiles fraction in RDF. 


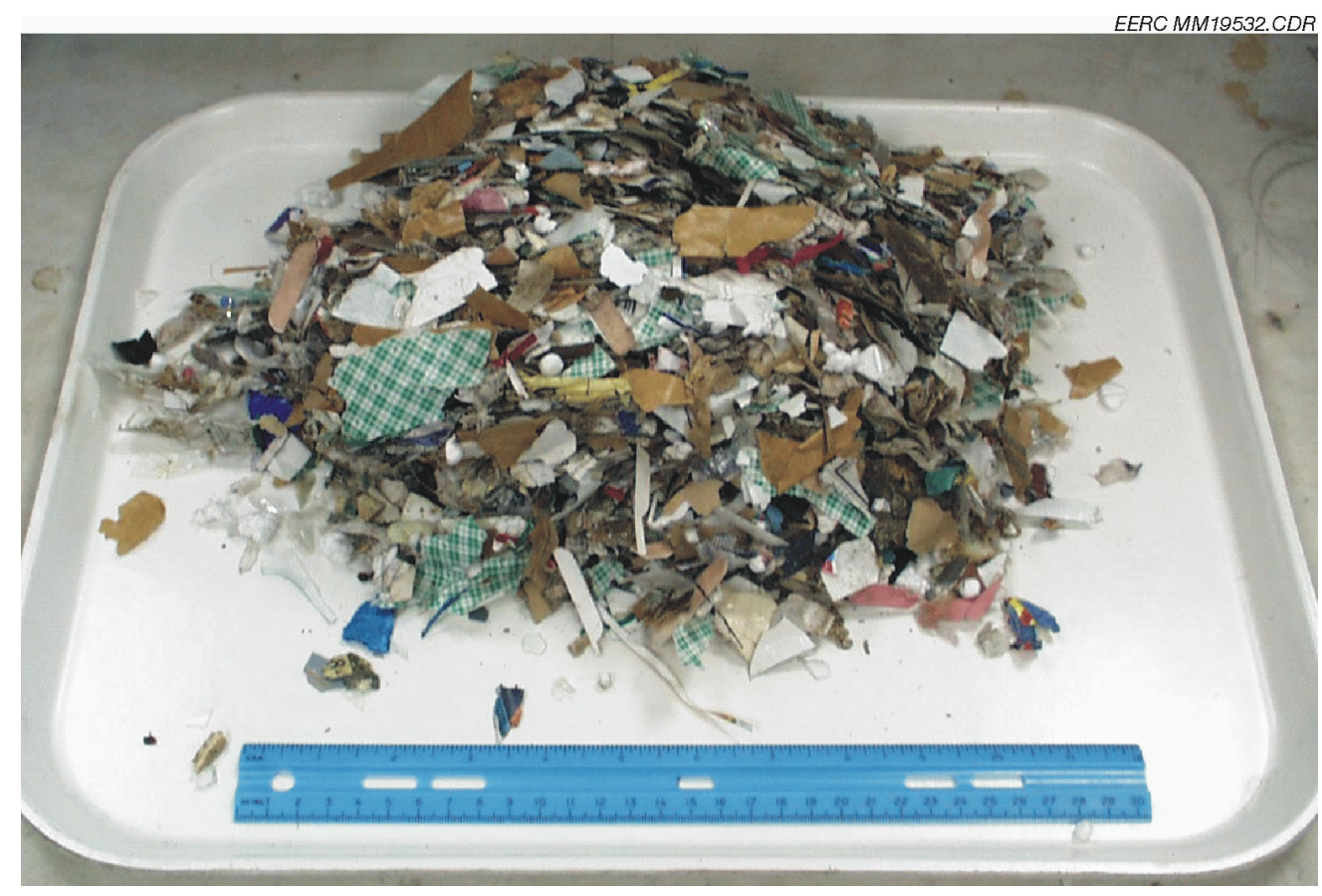

Figure C5. Fluff fraction in RDF.

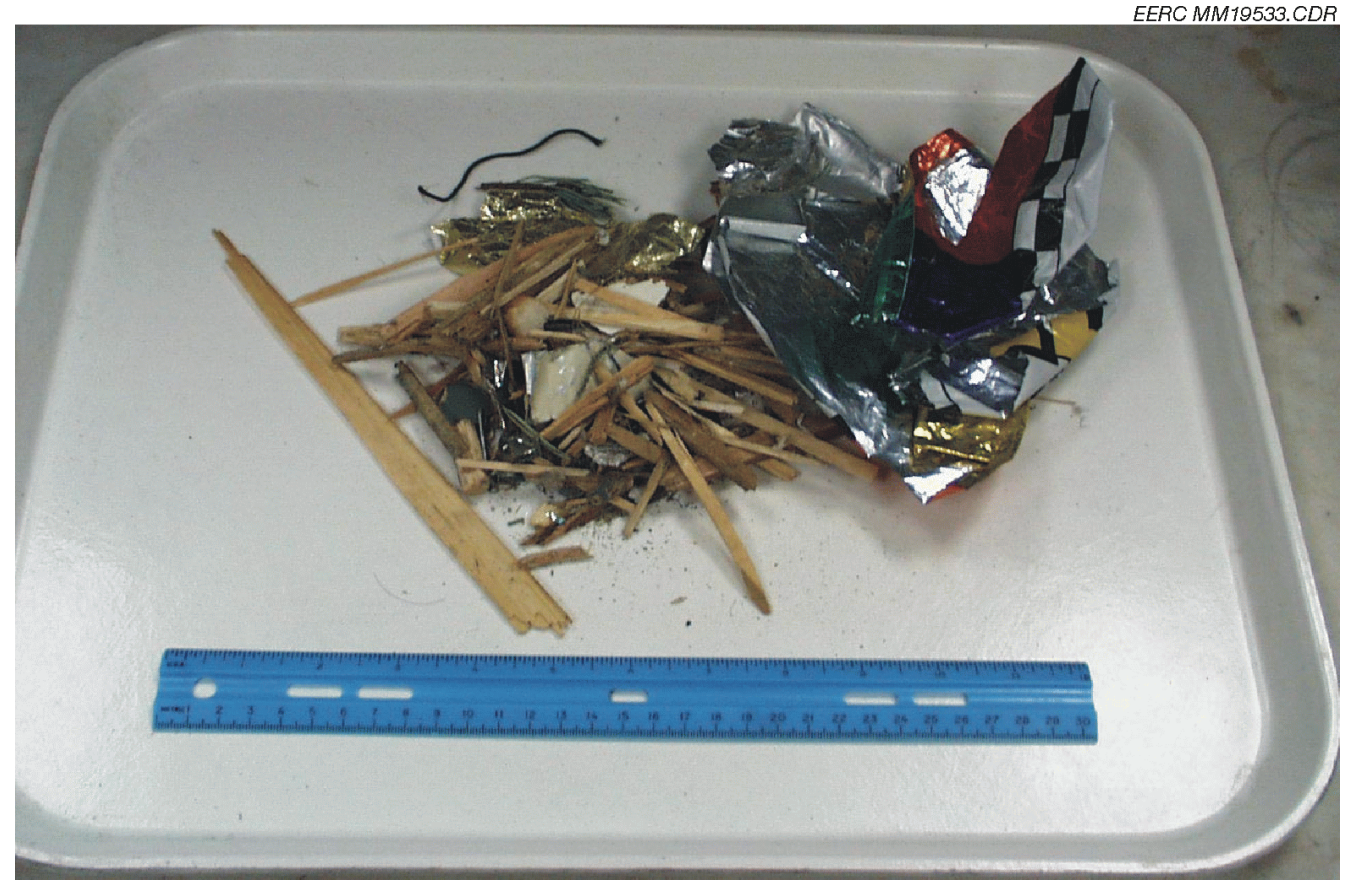

Figure C6. Combined wood, aluminum, ferrous, food waste, glass fraction in RDF. 


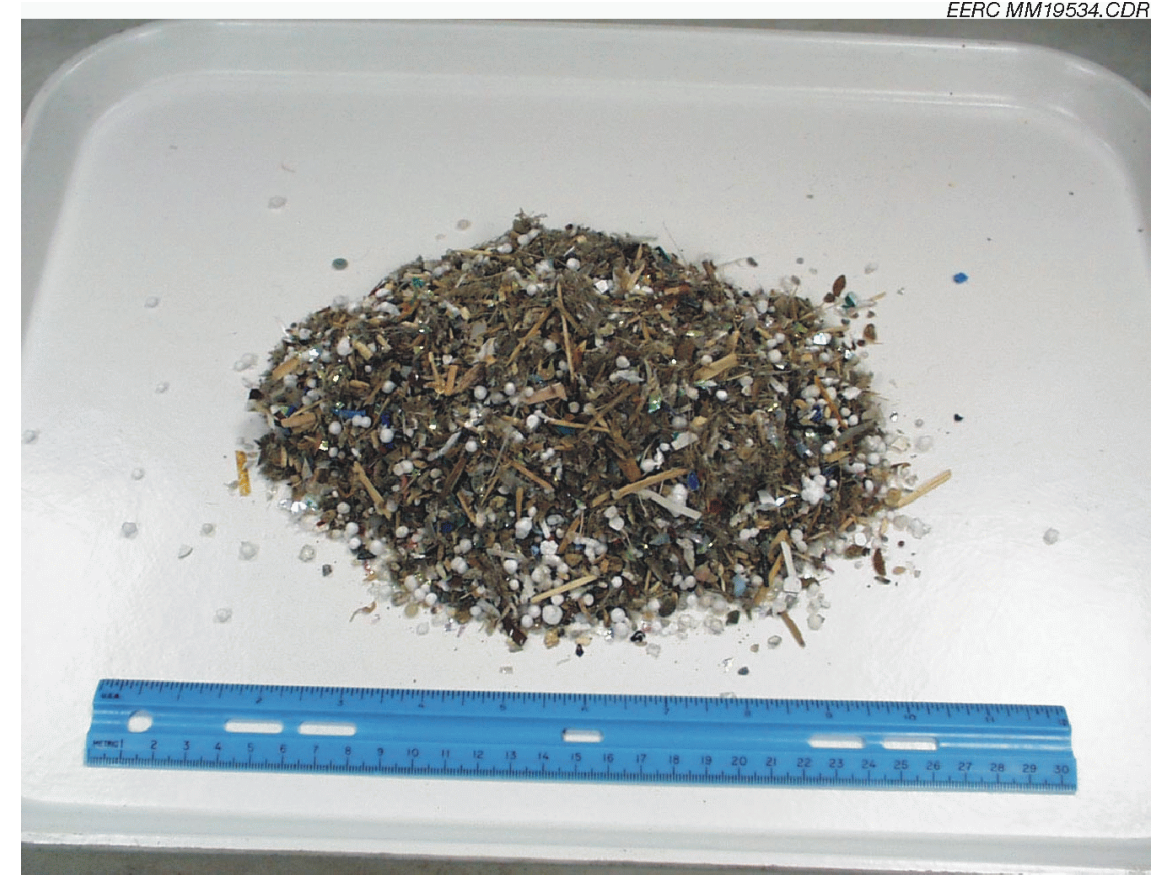

Figure C7. $-4-$ mesh $x+10-$ mesh fraction in RDF.

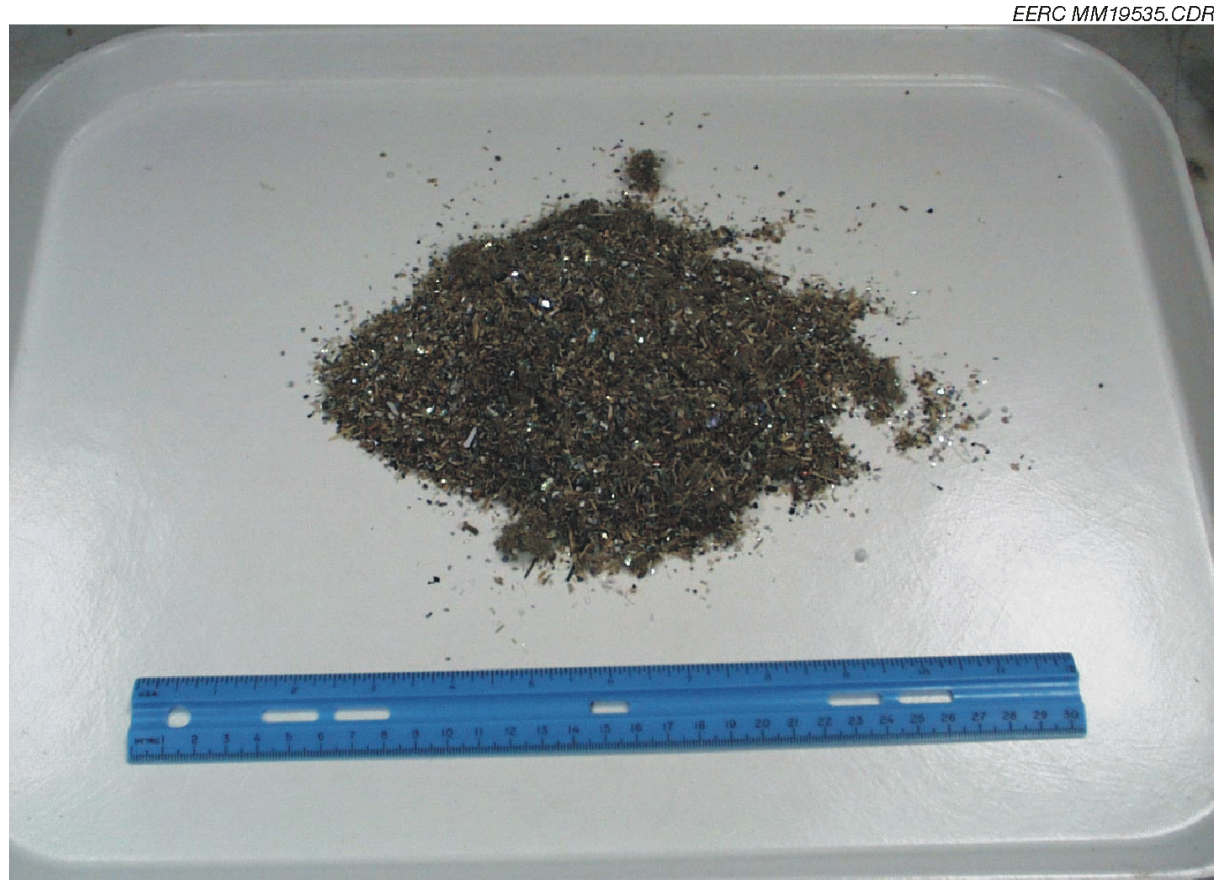

Figure C8. - 10-mesh $\mathrm{x}+20$-mesh fraction in RDF. 


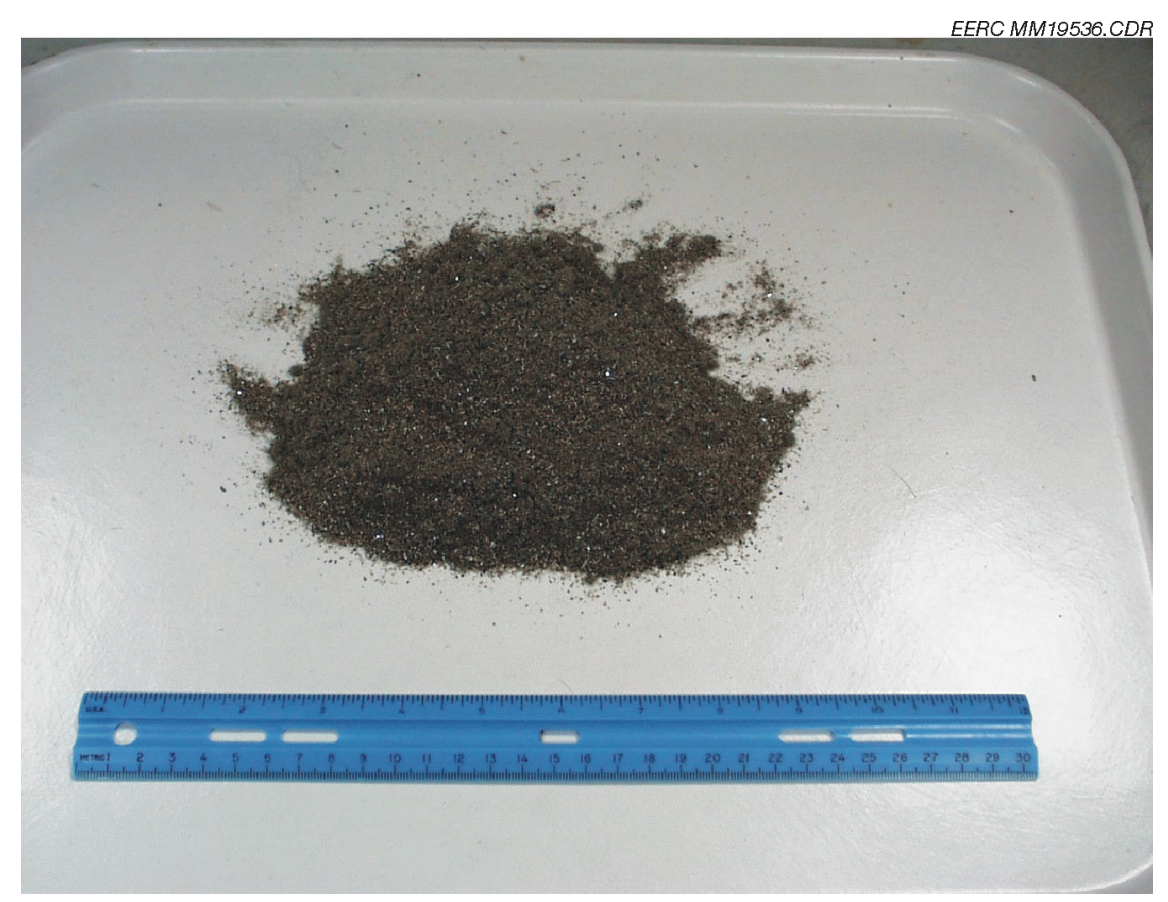

Figure C9. -20-mesh fraction in RDF. 